\title{
Regulating professionals in virtual practice: Protecting the public interest in rapidly changing digital workplaces
}

\author{
Knowledge Synthesis Grant Final Report
}

\section{AUGUST 2021}

\section{Research Team}

Kathleen Leslie, Assistant Professor, Athabasca University

Tracey L. Adams, Professor, Western University

Sioban Nelson, Professor, University of Toronto

Jacob Shelley, Associate Professor, Western University

Catharine Schiller, Associate Professor, University of Northern British Columbia

Sophia Myles, Research Assistant, Athabasca University

Aleah McCormick, Research Assistant, Athabasca University

Maggie Szu Ning Lin, Research Assistant, Athabasca University

Regulating professionals in virtual practice: Protecting the public interest in rapidly changing digital workplaces is co-funded by the Social Sciences and Humanities Research Council and the Government of Canada's Future Skills program », "La règlementation des professionnels en milieu virtuel: Protéger l'intérêt publique dans ces nouveaux environnement de travail virtuel est cofinancé par le Conseil de recherches en sciences humaines et le programme Compétences futures du Gouvernement du Canada. 


\section{Acknowledgements}

We gratefully acknowledge the valuable contributions of our research assistants: Sophia Myles provided insight and assistance throughout the research project and drafted portions of the final report; Maggie Szu Ning Lin and Aleah McCormick helped throughout the scoping review and formatted this report. We also thank Nicole Askin, library scientist, for her guidance and assistance on the search strategy for the scoping review phase of the knowledge synthesis. 


\section{Table of Contents}

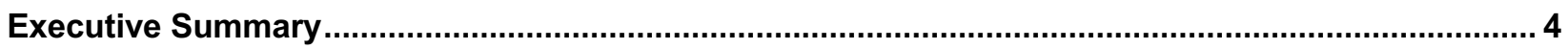

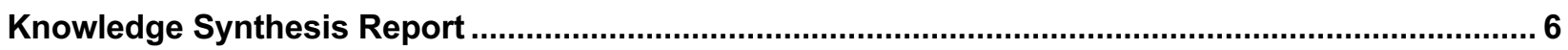

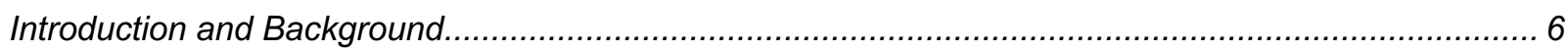

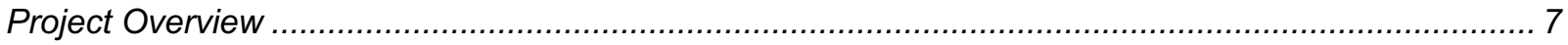

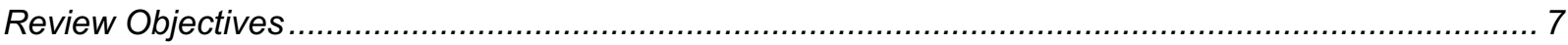

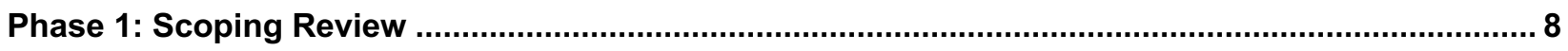

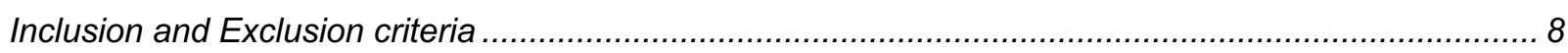

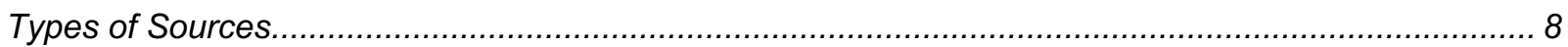

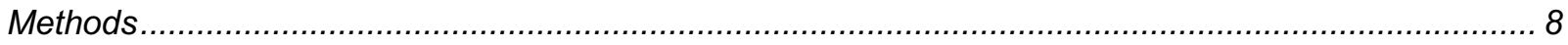

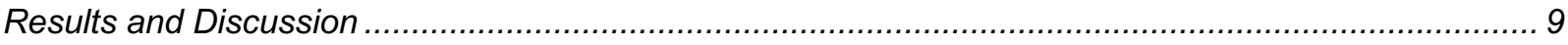

Phase 2: Deep Dive Policy Case Reports ..................................................................................... 18

CASE REPORT 1: Regulatory Sandboxes for Innovative Technology ....................................................... 18

CASE REPORT 2: For-profit Telehealth and Professional Regulation in Canada ........................................... 21

CASE REPORT 3: Interjurisdictional Registration Pilot Project for Nurses in Two Canadian Provinces................ 24

CASE REPORT 4: The Essilor case: Competition, Disruptive Technology, and the Public Interest...................... 26

CASE REPORT 5: Legal Professionals' Duty of Technological Competence..................................................... 28

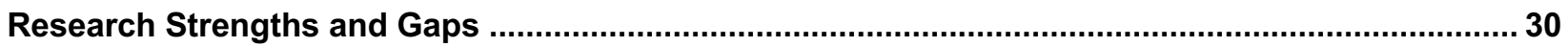

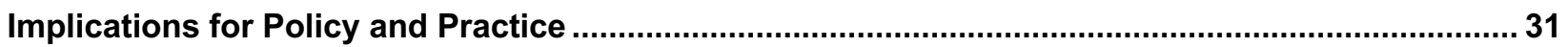

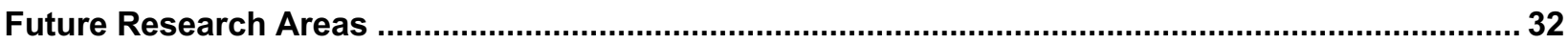

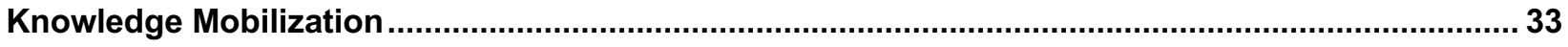

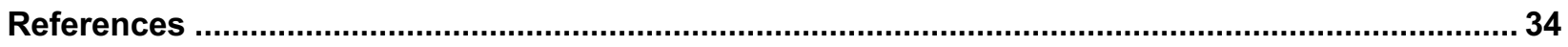

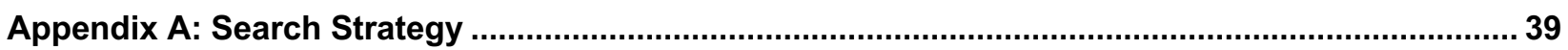

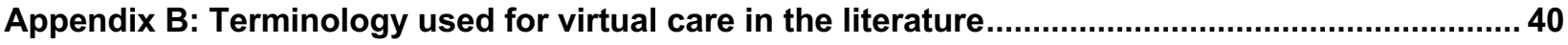




\section{Executive Summary}

\section{Background}

Virtual practice is transforming work in many professions, particularly with the accelerated shift to virtual work during the COVID-19 pandemic. Professional regulators face intense pressures to facilitate this work while upholding their legal mandate to protect the public. Challenges for professional regulators have included providing practice guidance for virtual care, changing entry-to-practice requirements to include digital competencies, facilitating interjurisdictional virtual care through licensure and liability insurance requirements, and adapting disciplinary procedures.

\section{Objectives}

The objective of this knowledge synthesis project is to examine how the public interest is protected when regulating professionals engaged in virtual practice, to discuss policy and practice implications related to professional regulation of virtual practice, and to make recommendations for future research.

\section{Methods}

The primary method of knowledge synthesis for this project was a scoping review. We followed $\mathrm{JBI}$ scoping review methodology. We retrieved extensive academic and grey literature from health sciences, social sciences, and legal databases. Two reviewers independently screened all titles and abstracts against the inclusion criteria for the review. Two independent reviewers then assessed full-text studies and excluded those that did not meet the inclusion criteria. Data were extracted from selected documents, and results were synthesized in a narrative format.

Throughout the scoping review, particular challenges and promising practices emerged regarding professional regulation of virtual practice. We developed five of these as deeper dive case reports in the Canadian context. These policy case studies include the use of regulatory sandboxes for innovative technology, the role of professional regulation in for-profit telehealth, pilot testing interjurisdictional registration for nurses, the potential anti-competition impact of regulatory restrictions on disruptive technologies, and the duty of technological competence in professional codes of conduct.

\section{Results}

- There was a clear focus on the health and social care professions in the literature on regulating virtual practice, and most articles reviewed were based in the United States and about physicians.

- The literature contained several definitions to interpret aspects of virtual practice, and numerous and varied terms based on a combination of profession or specialty, service provided, technology and tools used, area of care, client population, and location of care.

- Regulatory changes across professions related to virtual care proliferated during the 
COVID-19 pandemic, as governments and regulators sought to ensure access to virtual professional services while maintaining public protection.

- Critical to regulating virtual practice is the issue of cross-jurisdictional practice, and the literature identified regulation- specifically, licensure - at the subnational level as a barrier to equitable access to virtual professional services.

- When the public interest in virtual professional services was discussed, the dimension of "access to affordable services" was given most weight.

- The literature did not always touch on the public interest explicitly; hence there is a need for more research on the public interest in regulating virtual practice in Canada.

- There is a need to understand how the public can best be engaged in the regulatory process, particularly around understanding the public interest when receiving virtual professional services and how this should translate into regulatory policies and practices.

- Virtual professional services have the potential to improve quality and accessibility of services, but may introduce new areas of risk, potential harm, and inequity that regulators need to grapple with as technology-driven professional practice continues to evolve.

\section{Key Messages}

- The concept of the public interest continues to evolve in relation to virtual practice: Our review shows a focus in the academic literature on balancing public safety with equitable access to services and economic competitiveness to determine the public interest. This focus may continue to shift as we move into a post-pandemic world.

- Professional regulators have an important role in adapting to new technologies that impact professional practice and providing clear standards and guidelines around virtual practice: This should include what is required for competent practice since traditional definitions of competence and quality may be outdated in the era of digitally-enabled service provision.

- Professional regulators need to grapple with pressing and emerging virtual practice issues: Al-enabled practice, for-profit telehealth, and disruptive technologies were all raised in this review as having regulatory implications but remaining unresolved. The idea of a regulatory sandbox for innovative technologies should be considered in professions outside of finance and law, including in the health and social care professions.

- Governments and regulators need to consider how to facilitate virtual services across jurisdictional borders: Regulation at the subnational (provincial/territorial/state) level emerged historically to regulate providers providing in-person services locally; however, in the context of virtual service provision, this no longer holds true. To leverage virtual care to its fullest extent in both steady state and in the event of future global public health threats, it is important for governments to work with regulators to standardize the regulation of virtual care. 


\section{Knowledge Synthesis Report}

\section{Introduction and Background}

Technology is increasingly transforming service delivery in many professions, particularly with the rapid shift to virtual practice during the COVID-19 pandemic. Regulators face intense pressures to facilitate virtual practice while upholding their legislative mandate to protect the public. However, there are many legal and ethical complexities associated with regulating registrants who engage in virtual practice. The need to reform regulatory practices to meet these challenges to ensure access to safe and high-quality services has become more urgent given the impact of the COVID-19 pandemic on professional work. Professional regulators must act in the public interest, but how the public interest is defined is amorphous and subject to social change. The emergence of the digital economy may be shifting definitions of the public interest in professional practice and regulation, but precisely how remains unclear.

In recent years, professional regulation has come under scrutiny with the recurrent question of whether regulatory frameworks are truly protecting a modern public. This criticism - seen in recent academic work,(1-3) media reports,(4-7) and government inquiries (8-10)-highlights the complexities involved in defining the public interest in the context of exponential technological advances that have dramatically altered workplaces. Recently, policymakers and researchers have pushed for regulatory reform to be based on current evidence.(11,12) However, without an understanding of how the public interest is protected when regulating professionals in virtual practice, policymakers and regulators may not effectively deploy current research insights.

\section{Professional regulation and the mandate to protect the public}

In Canada, many professions are governed by self-regulatory bodies that are mandated to protect the public. The Supreme Court of Canada $(13,14)$ has upheld this principle of the paramountcy of the public interest. Indeed, it is often enshrined in the legislative framework empowering regulators (3) to protect the public against negligence, dishonesty, and incompetence by ensuring only those fit to practice safely are registered.(15,16) Professional regulators typically aim to meet this public protection mandate by setting entry-to-practice standards; maintaining a register of those who are licensed to practice; and monitoring and enforcing conduct, competency, and capacity in practice.(15) However, there has been debate and controversy about which activities should be included under this public interest mandate, and practices have varied over time. $(15,16)$

In the digital era, the social construct of the public interest will continue to be in flux. Regulatory activities in the public interest have changed to encompass the following: ensuring that standards provide necessary guidance for new models of digital work on topics such as consent, documentation, records management, and privacy; $(11,17)$ changing entry-to-practice requirements to include digital competencies; facilitating interjurisdictional virtual work through reciprocal licensure and liability insurance requirements; $(12,18)$ and adapting continuing 
competence requirements and disciplinary procedures to reflect modern digital environments.(19) The need to reform regulatory practices to meet these challenges in ensuring access to safe and high-quality services has become more urgent given the impact of the COVID-19 pandemic on professional work. Regulators need to respond to new technologies not because they are technological per se but because regulation needs to align with the new sociotechnical landscape, including possible negative features such as risk of harm, inequities, and market failures.(20) Thus, it is less about the technology itself than the impact on society when this technology is used, including in service provision for regulated professions.

\section{Regulating virtual practice: COVID-19 accelerates reform}

While participation in virtual practice for many regulated professions is not new, the COVID-19 pandemic has rapidly accelerated the uptake of this type of technologically driven professional work. The rapid scaling of virtual modes of work is a significant factor that distinguishes the response to the COVID-19 pandemic from previous public health crises or emergencies. Recent research has investigated the changes professions and professionals are experiencing with the increasing move to virtual service delivery in the rapidly evolving digital economy.(21-25) These changes to professional work necessitate changes to regulatory practices, but regulatory change has received little attention.

Throughout the pandemic, many regulated professions in Canada were deemed essential services, which entailed a strong push to scale virtual service provision. Regulatory reforms across professions rapidly proliferated as regulators balanced increased flexibility with public protection. The reforms related to regulating virtual practice were fast-tracked, but calls have been made for regulatory frameworks to be subject to careful post-implementation reviews-a means to ensure the public is protected.(18) Others have argued that relaxing regulatory barriers during the pandemic demonstrates that these requirements were unnecessary for public protection in the first place and have called for changes to be retained post-pandemic. $(19,26,27)$ Whether these regulatory reforms contribute to public protection in the short, medium, and longterm requires a synthesized understanding of regulating virtual practice in the public interest.

\section{Project Overview}

In Phase 1 of this knowledge synthesis, we conducted a scoping review following JBI methodology and the PRISMA-ScR checklist for scoping reviews. Throughout the scoping review, specific challenges and promising practices emerged regarding professional regulation of virtual practice. In Phase 2 of the knowledge synthesis, we have drawn five of these out to provide a deeper dive into specific Canadian examples and contexts.

\section{Review Objectives}

The objective of this knowledge synthesis project is to examine how the public interest is protected when regulating professionals engaged in virtual practice, to discuss policy and practice implications related to professional regulation of virtual practice, and to make recommendations for future research. 


\section{Phase 1: Scoping Review}

\section{Inclusion and Exclusion criteria}

\section{Participants}

We included studies involving any regulated professionals, defined here as those governed by professional regulators with the legal mandate to protect the public. While much of the dialogue around regulating virtual practice focuses on health professions, we included regulated professions outside of health to add to the breadth and scope of this interdisciplinary review.

\section{Concept}

We included studies that contributed to the concept of protecting the public interest when regulating professionals in virtual practice. Protecting the public interest is sometimes described as ensuring patient or client safety, but the public interest is often conceptualized more broadly in the Canadian context. We included any form of professional service delivery where there was no in-person interaction in searching for literature on virtual practice.

\section{Context}

This review considers studies that discuss protecting the public interest when regulating professionals in virtual practice in any country or setting. Functions of regulatory authorities that contribute to public protection include setting entry-to-practice and registration requirements, monitoring conduct and competency in practice, and sanctioning negligence or misconduct by individual professionals. We excluded articles focused on other types of government or industry regulation such as pharmaceuticals, medical devices, or provider reimbursement.

\section{Types of Sources}

We considered any type of study design for inclusion. English-language grey literature in the public domain that specifically discussed regulating professionals in virtual practice (such as legal briefs, government reports, documents from regulatory consortiums or umbrella organizations, and policy papers) were also considered for inclusion. We excluded letters to the editors, practice guidance or standards from specific regulators, textbook chapters, and conference abstracts.

\section{Methods}

\section{Search strategy}

The literature around professional regulation of virtual practice is diverse and we wanted to capture various disciplinary perspectives. As such, we searched academic databases that covered health science literature (MEDLINE [Ovid], and Embase [Ovid]), social science literature (Sociological Abstracts [Proquest], Social Work Abstracts [EBSCO]) and legal literature (HeinOnline, CanLII, and WestlawNext Canada) as well as the interdisciplinary database Scopus and search engine Google Scholar. In addition, we conducted an iterative grey literature search strategy including grey literature databases (OpenGrey, Nexis Uni, ProQuest 
Dissertations and Theses Global), search engines (first 200 Google results), and relevant websites (e.g., COVID-19 Law Lab, OECD Regulatory Policy Division, GovInfo, and Government of Canada) based on keywords used in the academic database searching and in consultation with the research team. We draw primarily upon this grey literature in the deeper dive case reports in Phase 2 of the knowledge synthesis.

We conducted an initial limited search of the CINAHL and Scopus databases to identify a selection of relevant articles on the topic. We then worked with an experienced academic librarian to adapt the search strategy across the various databases using a comprehensive matrix of search terms. Articles written in English and published from 1 January 2015 to 29 May 2021 were considered for inclusion to capture the most recent evidence given the rapidly evolving nature of telehealth and virtual practice. A full search strategy for MEDLINE (EBSCOhost) is in Appendix A.

\section{Study Selection}

Following the search, we uploaded all identified records into the review management software Covidence and removed duplicates. Two reviewers independently screened all titles and abstracts against the inclusion criteria for the review. Two independent reviewers then assessed full-text studies and excluded those that did not meet the inclusion criteria. Any disagreements between reviewers were resolved through discussion or by a third reviewer.

\section{Data Extraction and Analysis}

Data were extracted from included studies and grey literature by one reviewer and verified by a second reviewer. We extracted data using a modification of the JBI data extraction tool developed for this scoping review by the research team. The data extracted included details about the population (e.g., the specific regulated profession), the concept of regulating professionals working in virtual practice, the context of regulatory activities in the public interest, geographic location, and key findings relevant to the review objectives and question. We have narratively summarized the extracted data to describe the literature.

\section{Results and Discussion}

\section{Academic study inclusion}

The academic database searches and other source retrievals resulted in 4236 records after we removed duplicates. After screening titles and abstracts, we assessed 155 full-text papers for eligibility, 92 of which were excluded based on our inclusion criteria. A total of 63 academic articles were included in our final review. See Figure 1. 


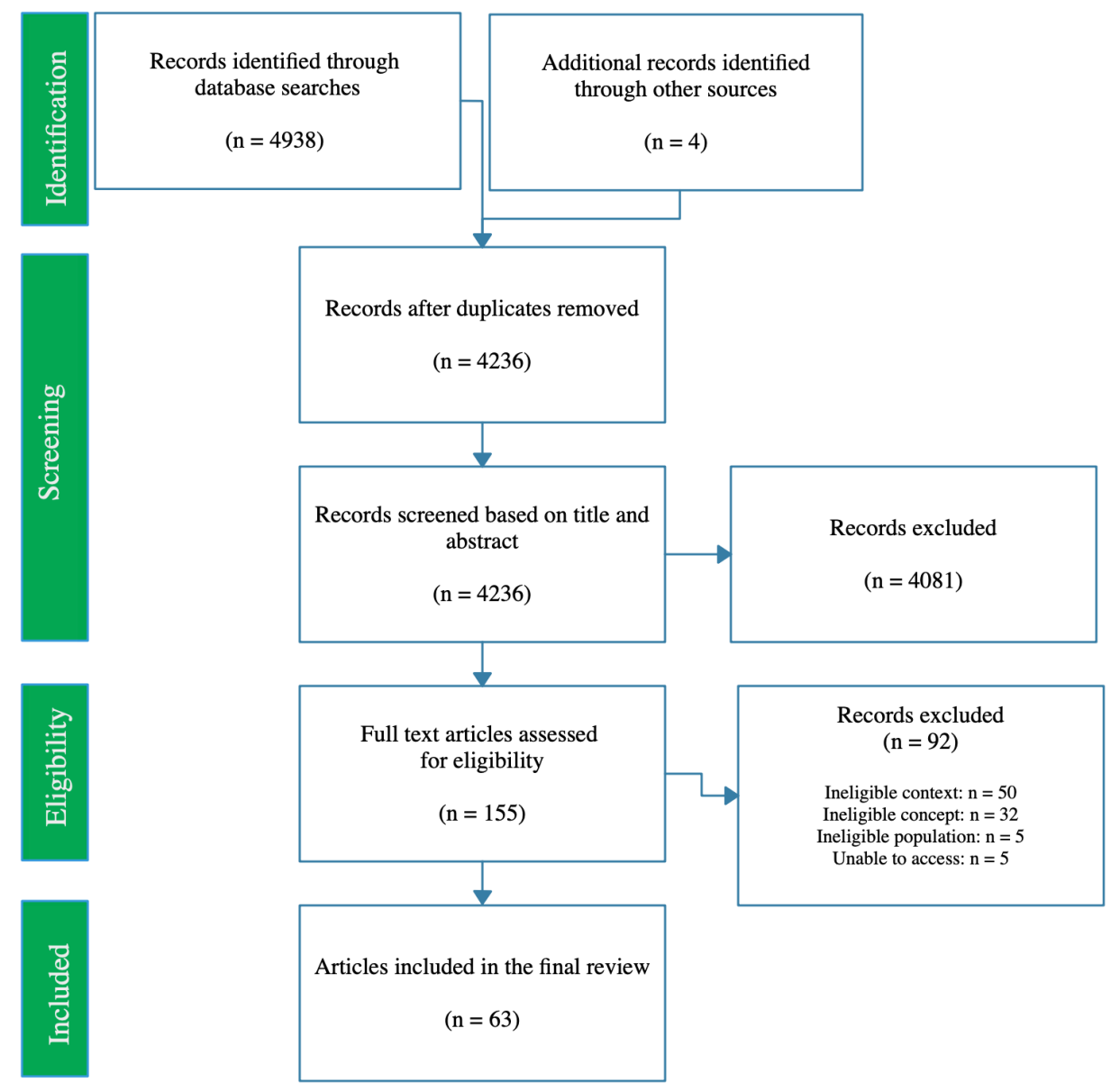

Figure 1: Search results and study selection and inclusion process.(28)

\section{Characteristics of included academic articles}

Academic literature included in this review consisted of the following types of papers: opinions/commentaries/perspectives/debates/expert reports $(n=24)$; reviews including metasyntheses, narrative reviews, literature reviews and scoping reviews $(n=13)$; legal research notes/analyses/reviews $(n=8)$; descriptive/observational studies $(n=3)$; qualitative studies $(n=2)$; case reports/studies $(n=1)$, and other article types $(n=8)$. Professional regulation of virtual practice was predominantly discussed in the context of healthcare, with all but four articles focused on health or social care professionals. The four academic articles outside of health focused on lawyers, specifically the regulatory requirement of technological competence and regulating legal professionals working in the era of artificial intelligence.

Geographically, most of the academic papers focused on the United States $(n=47)$. The geographic contexts of the remaining articles were Canada $(n=2)$, India $(n=1)$, Hong Kong $(n=1)$, Brazil $(n=1)$, South East Asia $(n=1)$, as well as articles with an international focus including Europe and the European Union (EU), Australia, Portugal, and Russia $(n=10)$. 
Most of the articles focused on physicians $(n=34)$ and specialties or services, including radiology, psychiatry, surgery, dermatology/dermatopathology, and doctors providing telemedicine abortions. Professional populations highlighted in the remaining articles were nurses (registered nurses, nurse practitioners, advanced practice registered nurses); dentists, oral and maxillofacial radiologists, and allied dental providers (i.e., dental therapists); pharmacists and pharmacy technicians; allied health professionals (e.g., occupational therapists, physical and physiotherapists, speech language pathologists), and mental health professionals (e.g., psychologists, social workers). Additionally, a few articles discussed regulated health professionals or health providers more generally or across the spectrum.

\section{Variable terminology to describe virtual practice}

The literature contained several definitions to interpret aspects of virtual practice, including remote services, telehealth, telemedicine, and virtual care. We noted numerous and varied terms in the articles based on a combination of profession or specialty; service(s) provided; technology and tools used to provide services and the functions they perform; area(s) of care; client population(s) served; location(s) of care (i.e., health unit, department, client residence); proposing new specialists; and connecting clients and providers at a distance. Telemedicine and telehealth were most frequently used to discuss virtual practice in relation to the health professions. While telemedicine was used more frequently in the past, there is a movement, in the United States at least, to phase out this term in favour of telehealth.(29) The various terms found in our review to describe virtual practice are listed in Table 1. We provide further details on the definitions of these terms in Appendix 2.

\begin{tabular}{lll} 
Table 1: Terms Used in the Literature to Describe Virtual Practice & \\
Connected care & Tele-coaching & Teleneurology \\
Cybermedicine & Telecollaboration & Telepathology \\
Digital health & Teleconsultation / & Telepharmacy \\
Digital technologies & Teleconsulting & Telephone nurse / nursing \\
Digital tools & Telecommunication(s) & Telephonic care \\
e-connected care & Telecommunications & Telepsychiatric care / \\
eHealth & technologies & Telepsychiatry \\
Geriatric telemedicine & Teledentistry & Telepsychology \\
Information and & Teledermatology & Teleradiology \\
communications technology & Teledermatopathology & Telerehabilitation \\
Information technology & Telediagnosis / & Tele-support \\
MHealth & Telediagnostic & Telesurgery \\
Medical virtualist *proposed & Tele-education & Tele-treatment \\
new specialist & Tele-homecare & Televisit \\
Remote consultation & Telehealth & Virtual care \\
Remote intervention & TelelCU & Virtual consultation \\
Remote patient monitoring & Telemedicine & Virtual presence \\
Technology & Telemedicine abortion & Virtual services \\
Telecardiology & Telenursing & Virtual technology \\
Telecare & Telemental health & \\
\hline
\end{tabular}




\section{Regulatory Context and Activities}

The expansion of virtual service provision raises many challenges, some of which regulators are just beginning to grapple with. The literature we reviewed, however, did not always specifically articulate public interest concerns in regulating virtual practice; at times public interest considerations are only implied by the regulatory activities (e.g., preventing worsening of public health epidemics due to relaxed prescribing rules (30) and unlawful, incompetent, unethical, fraudulent, abusive or negligent practice using remote/virtual modalities of service delivery.(3137) The literature highlighted several issues that impact the public interest, especially geographic and health population barriers created by current regulatory structures. Articles also used terms such as protecting or enhancing public safety, health and welfare in the context of regulating professional practice.

The literature primarily focused on licensure as a regulatory activity when discussing virtual practice. Other regulatory activities included certification, credentialing and privileging; the issuance of emergency orders and waivers during COVID-19; scope of practice; practice standards (including ethics and maintaining competence); standard(s) of care; duty to care; consulting with other providers; privacy, security, and confidentiality; informed consent; and providing guidance to the profession.

Articles identified that regulators needed to provide clarity around the expected standard of inperson and virtual care, the establishment of the practitioner-client relationships,(38) managing ethical issues in virtual care provision, and (for legal professionals) the ambit of the duty of technological competence. Regulators have an important role in providing guidance on how the duties provided in professional codes of ethics (such as, for lawyers, independence, integrity, and the exercise of professional judgment) intersect in relation to specific technologies.(39) Recognizing this, umbrella regulatory consortiums have offered guidance, model codes, and support for memorandums or agreements for virtual care practice standards. In Canada, the

Licensure compacts

Licensure compacts have proliferated in the United States to overcome the barrier of needing multiple licenses to provide services across state borders. In licensure compacts, specific providers can practice in states where they do not hold a license, as long as they hold a license in good standing in their home state. In the literature we reviewed, the most discussed compacts were the Interstate Medical Licensure Compact, the Nurse Licensure Compact, the Advanced Practice Nurses Licensure Compact, and the Psychology Interjurisdictional Compact. There is also a compact in the US for physical therapists, audiologists and speech language pathologists, and emergency medical service personnel. In 2021, five new compacts were announced as under development: social work, dentistry and dental hygiene, massage therapy, K-12 teaching, and cosmetology and barbering. $(42,43)$
Canadian Alliance of Physiotherapy Regulators established a cross-border physiotherapy memorandum of understanding to facilitate access to telerehabilitation.(40) The Federation of Medical Regulatory Authorities of Canada is exploring the potential for a specific telemedicine license, a short duration license for portability, or a fast-tracked license agreement for physicians already licensed in another Canadian jurisdiction.(41) In the United States, these regulatory umbrella organizations such as the National Council of State Boards of Nursing and the Federation of State Medical Boards have been instrumental in the proliferation of interstate licensure compacts. $(42,43)$ 


\section{COVID-19 as a Catalyst for Licensure and Scope of Practice Changes}

The expansion of virtual professional practice is anticipated to be an "enduring legacy" of COVID-19 in a pandemic recovery and post-pandemic world.(38) Regulatory reforms across professions proliferated during the COVID-19 pandemic, as regulatory bodies sought to ensure access to virtual professional services while maintaining public protection.

In the United States, executive orders from state governors have been used to temporarily lift licensing requirements to solve workforce shortages related to an emergency. According to the National Conference of State Legislatures (2020), prior to the 2020 COVID-19 pandemic, three governors had used executive orders for this purpose but during the pandemic, all states took some sort of action to ease licensing requirements and meet workforce needs caused by the pandemic (most acutely seen in health care and emergency response occupations). There was a stronger push for states to join licensure compacts, and a bill was introduced in Congress in November 2020 that would penalize states that did not join the IMLC within the next three years. (44) This bill also proposes blocking state medical boards from receiving certain federal grants if they did not have a public awareness campaign encouraging specialist physicians to practice telemedicine.(44)

The Health and Human Services Secretary in the United States may waive telehealth restrictions during a public health emergency, and this was used during the COVID-19 pandemic. For example, before the pandemic, federal regulations limited the scope of pharmacist services that could be provided via telehealth. However, to enhance flexibility and facilitate broader access to care during the pandemic, legislation was passed which permitted pharmacists, among other credentialed providers, to provide broader telehealth services to clients with fewer restrictions.(45)

Similar changes were made in Canada, with provinces and territories relaxing criteria around registration to enhance surge capacity, particularly in the health care system. Some of these regulatory changes were to facilitate virtual professional services that may not have been authorized prior to the pandemic. For example, to maintain continuity of care, the Newfoundland and Labrador Psychology Board authorized out of province psychologists to provide virtual services to clients who were in the province due to the emergency by completing a simple form (Newfoundland and Labrador Psychology Board, 2020). The professional regulator for lawyers and paralegals in Ontario facilitated emergency Orders in Council to allow virtual execution and witnessing of wills,(26) provided legislative interpretation regarding virtual client identification,(27) and guided licensees about requirements for virtual notarizing and commissioning.(2) In January 2021, the regulator for nurses in Ontario began the process of modernizing all practice standards to ensure relevance to new areas of practice and risk.(1) 


\section{Emphasis on Access in Defining the Public Interest}

When the public interest in virtual professional services is discussed, it is the dimension of "access to affordable services" that is given most weight. Indeed, telemedicine and telehealth have been traditionally used to address health disparities and facilitate access to affordable health care in rural and remote areas to address health disparities and health workforce

Regulatory sandboxes

A regulatory sandbox is a "safe space"

that is established and overseen by a

particular regulatory body. Contrary to

the common view of regulation as a

barrier or hindrance to technological

advancement and product testing,

regulatory sandboxes are intended to use

regulation as support for ensuring

responsible innovation (Leckenby et al.,

2021). The use of regulatory sandboxes

for innovative technologies is explored in

Case Report 1. shortages. $(46,47)$ Increasing health care access in underserviced areas is thought to improve public health and welfare overall.(46) As the use of telehealth continues to become more ubiquitous in pandemic recovery and the post-pandemic world, a challenge for professional regulators will be to continue to adapt as virtual practice evolves to ensure quality, competent care, and consumer safety. One possibility for managing this challenge is a regulatory sandbox as a mechanism for regulators to support and oversee innovative technology. This is explored in Case Report 1.

There is also a growing public expectation around access to virtual professional services. In law, the professional model of practice has shifted away from the lawyer as expert ascendant over the client to a consumer-focused orientation, and developments in legal technology are being driven by clients' demands for efficiency and cost-effectiveness.(39) In health care, this is similar, with the OECD noting that societies across the globe are going digital and health care consumers are increasingly expecting the same level of responsiveness and ease of use in health care as in other digital technologies.(48)

The extent to which the intent of professional regulation is fulfilling its mandate to act in the public interest as it pertains to virtual practice was questioned in the literature. In the American context, legal and regulatory mechanisms may unduly restrict some providers and clients from delivering and accessing medically necessary services. For example, while acknowledging the merits of licensure compacts to facilitate the provision of and access to virtual care, current IMLC standards permit approximately $80 \%$ of physicians to be eligible for licensure through the Compact. $(31,38)$

Alternatively, opposing concerns regarding the potential exacerbation of public health epidemics have been raised about the easing of teleprescribing restrictions for controlled substances (thus enhancing access to addictive or illegal gateway drugs) without first conducting an in-person examination.(30) A number of articles highlighted two court cases and resulting legislation (e.g. Ryan Haight Online Pharmacy Consumer Protection Act, 2008; Hageseth v. Superior Court, 2007) regarding online prescribing of controlled substances or other medications without an initial in-person exam.(34,49-51) In the international context, there are numerous restrictions on medications that can be prescribed through telepsychiatry (e.g. sleep aids, antipsychotics). Prior to the pandemic, Australia, South Africa, Spain and the UK had uniform rules for in-person 
and teleprescribing. While restrictions in a number of jurisdictions for remote prescribing were relaxed in part due to the pandemic, there were still more restrictions on telepsychiatry prescriptions than prescriptions for in-person appointments in regions with added remote prescribing restrictions.(52) Regulators understandably have quality and safety concerns for psychiatric care delivered by telehealth. Evidence regarding the extent to which these concerns are founded is mixed. Studies have reported tendencies for overprescribing medications without in-person contact, $(53,54)$ yet have also found a general equivalence between telehealth services and in-person care. $(54,55)$

These examples in the literature call attention to the potential unintended consequences of reduced access created by current regulatory structures when attempting to protect the public's health and well-being. They also raise questions about how much importance should be placed on how the practitioner-patient relationship is established to deliver and access medically necessary care. In addition to questions surrounding whether regulators are fulfilling their mandates, the literature we reviewed was critical of the extent to which regulators are acting in the public interest when certain regulatory decisions have the result of reducing access to service. A commonality behind each of these criticisms is that they inhibit more widespread use of telemedicine.

These criticisms found in the literature tend to fall under three areas:

\section{Turf Protection, Professional Interests, and Anti-Trust Actions}

Requiring patients or clients to travel for services that can be provided virtually raises concerns that regulators are acting in the interests of professionals to reduce competition for local providers. Many states limit health providers from practising telemedicine by requiring them to be licensed in the state in which the client resides. $(53,54)$ This and similar practice limitations may be subject to federal anti-trust (competition law) challenges. Some papers highlighted two anti-trust cases in the United States that involved professional regulators: Teladoc v Texas Board of Medicine and North Carolina State Board of Dental Examiners v Federal Trade Commission. We dive deeper into the application of these concerns in the Canadian context in our Phase 2 Case Reports.

\section{Politics Superseding Science to Drive Decision-Making}

Restrictions on telemedicine abortion in the United States have led to suggestions that there has been a shift in the core functions of state medical boards, that their authority to make decisions has become too broad and has gradually expanded to include a more invasive role into medical practice.(56) Certain restrictions on politically controversial services via telemedicine were criticized as being motivated by politics rather than science, thus resulting in questionable telemedicine policy.(56) The example most commonly discussed in the literature was a practice standard instituted by the lowa Board of Medicine that prohibited telemedicine abortion. In a legal challenge brought by Planned Parenthood, the lowa Supreme Court found that the medical board singled out 
medical abortion despite evidence that the number of abortions and adverse outcomes do not increase when this service is provided by telemedicine.(57) In Canada, there have not been similar assertions of political influence in decision making. A protocol released early in the pandemic by the Society of Obstetricians and Gynecologists of Canada provided guidance on telemedicine abortion in Canada and did not suggest any inperson visit requirements.(58) To our knowledge, access to politically controversial services by virtual means has not been restricted by Canadian regulators.

\section{Requiring Licensure in Multiple Jurisdictions Creates Economic Inefficiencies} While registration or licensing fees are required to support regulatory programs and activities, requiring professionals to pay licensing fees in multiple jurisdictions potentially creates undue time and financial burdens to provide and access telemedicine services. Obtaining and maintaining licenses for multiple jurisdictions is costly and time-consuming for providers, $(59,60)$ and arguably raises costs for consumers, thereby impacting equitable access.(61) Regulators in Canada are just beginning to grapple with these issues.

\section{Subnational Occupational Licensure as a Barrier to Virtual Care}

Critical to regulating virtual practice is the issue of cross-jurisdictional practice. The literature identified regulation at the subnational level in both Canada and the United States as a significant barrier to equitable access to professional services, particularly during the COVID19 pandemic. This was the most consistent point raised across the included academic articles.

Professional regulation originally emerged at the subnational (state/provincial/territorial) level to govern services provided locally, as well as to address regional concerns and to reflect local cultures and concerns. However, technologies now facilitate cross-regional practice and the highly variable geographic approach to licensure and registration has become increasingly problematic and difficult to defend.

In Canada, where the constitutional division of powers has provided provinces and territories authority to regulate most professions, calls have been made to address the variability in the approach to professional regulation across provincial and territorial borders. $(62,63)$ Despite some regulatory reform around virtual care, variations in licensure requirements and scopes of practice, as well as difficulties ascertaining to which regulator professionals are accountable have continued to complicate virtual cross-jurisdictional practice. $(4,14,64)$ A pilot for interjurisdictional registration for nurses in two Canadian provinces is currently underway (see Case Example 3 in Phase 2). Another example to watch is the new national Canadian regulatory authority for patent and trademark agents, becoming operational in June 2021.(65) This national regulatory authority, intended as a "new, state of the art public interest regulator of the intellectual property professions" conducts its regulatory operations virtually without a central office.(66) 
In the United States, the state-based system of occupational licensure has created a confusing web of virtual practice requirements across different professions. For example, the FSMB regularly updates its information on states that have modified licensure requirements to support telehealth in response to the pandemic and this document, at the time of writing, was 22 pages of detailed information of the regulatory variations between states.(67) Following multiple state standards of care to provide telemedicine services out-of-state raises liability risks and likely prevents broader telemedicine use.(68)In the United States, like in Canada, this variability has been subject of debate and calls for national regulation of telemedicine standards of practice through either the federal government's commerce power or spending power. Several papers identified and discussed the development of national licensure systems and licenses as a possible solution to the barriers and other inefficiencies imposed by state licensure.(6972) Achieving this would require the successful navigation of political and legal difficulties.(69) However, some exceptions to state jurisdiction over licensure exist. Some federal health programs permit out-of-state clinicians to provide telemedicine services within the Veterans Affairs system.(70) This may have been eased due to the salaried nature of Veteran Affairs health care providers: while not the focus of our review, the varying models of reimbursement for health services across state borders and internationally, particularly the common fee-for-service model, complicates moves to standardize telehealth and this was recognized in the literature as a barrier to virtual care.

Subnational occupational licensure can inhibit the growth, implementation, and more widespread use of telemedicine domestically and internationally.(73) The literature demonstrated the value of policy harmonization and cooperation in the global digital economy. As the only developed countries that do not have a national licensure system, Canada and the United States (72) can look to other countries and regions to see how they have adapted their systems of occupational licensure and have embraced new technologies for professional practice in the $21^{\text {st }}$ century.(71) For example, Australia has a national agency that is responsible for the regulation and accreditation for 15 health professions.(74) Also, the European Economic Community recognizes sectoral professions including medicine, dentistry, nursing, pharmacy, and midwifery of member states to facilitate labour mobility, and the EU has a system of regulation which automatically recognizes professional qualifications allowing credentialed professionals to lawfully practice in any member state.(75) To enhance the global use of telemedicine, it is necessary to work towards standardized virtual care law and policy, addressing issues of regulation, licensure, liability, and reimbursement. 


\section{Phase 2: Deep Dive Policy Case Reports}

Throughout the scoping review, particularly in the grey literature, certain challenges and promising practices emerged regarding professional regulation of virtual practice. We have drawn several of these out to provide a deeper dive into specific Canadian examples and contexts.

\section{CASE REPORT 1: Regulatory Sandboxes for Innovative Technology}

\section{Brief Overview}

The COVID-19 pandemic has accelerated the development and adoption of technology within the healthcare system. Some of this technology became incorporated into practice very swiftly in direct response to immediate user need, at times without appropriate regulation or evidence of benefit. $(76,77)$ For example, the option of meeting with one's healthcare provider via Zoom, FaceTime, or other digital communication platform quickly became an option during the pandemic before it was confirmed that privacy and security requirements could actually be assured. However, as jurisdictions now begin to focus on post-pandemic reopening, they are considering different ways that digital advancements in healthcare could be actively encouraged while still being safely incorporated into the public domain.

One of these options is a regulatory sandbox, a "safe space" that is established and overseen by a particular regulatory body. Contrary to the common view of regulation as a barrier or hindrance to technological advancement and product testing, regulatory sandboxes are intended to use regulation as support for ensuring responsible innovation.(78) Organizations or individuals apply to take part in the sandbox, describing their innovation, its application, and their objectives to be met. The regulatory body sets criteria for the selection of projects that will take part in the sandbox, creates rules and safeguards for their participation, and closely monitors their activities. Those who are selected to try out their innovations through the sandbox can then "experiment and test...products, services, business models and delivery mechanisms in a live market with real consumers", (49 p2) and with ongoing guidance from the associated regulatory body.(80) Because participation in the sandbox is time-limited, testing is carried out on a small scale with a limited number of clients compared to a full launch of the innovation.(79) This process not only helps to determine feasibility and safety of the bigger project, but also helps ensure that appropriate safeguards have been built into the delivery of the product or service without the risk of normal regulatory consequences.(78)

\section{History / Context}

The concept of a regulatory sandbox originated in the United Kingdom financial technology sector in 2015. It was based on the pharmaceutical industry approach of testing biomedical advances through clinical trials that allow both testing and monitoring to be done in a safe, controlled environment.(78) It is therefore still a fairly new idea with less than five years of realworld application.(77) Nonetheless, the idea of a regulatory sandbox has quickly expanded to 
many different industries (including healthcare, construction, and law) and countries across the globe (as varied as the United States, Singapore, and South Korea). The first industry and jurisdiction in Canada to adopt a regulatory sandbox was the Law Society of British Columbia, which launched a regulatory sandbox program for legal technology innovation at the end of 2020 and currently has six approved participants providing products and services under the auspices of the program. The purpose of this program is to encourage "unorthodox"(81) ideas or structures that are not currently allowed by regulation but that could be used to address an access-to-justice gap in the province. The Law Society of Ontario recently announced their own regulatory sandbox for the purpose of encouraging innovative technological legal services to improve service delivery and access.

The possibility of using regulatory sandboxes for testing and assessing virtual healthcare initiatives, such as telehealth, within the United States healthcare system was recently proposed by Walsh (2021) and more broadly examined by Leckenby et al. (2021).(77,78). Closer to home, Health Canada recently communicated its intention to incorporate a regulatory sandbox into its new Advanced Therapeutic Products (ATP) pathway. ATP products are defined as "drugs or devices that...current regulations were not designed to handle because they're so novel, complex and distinct".(83) This ATP initiative was specifically built on recent changes to the Canadian Food and Drugs Act, which allow for a more agile regulatory response to new technologies.(84)

\section{Regulatory Implications}

The regulatory sandbox approach is rapidly gaining traction in a world made anxious by the COVID-driven pace of technological change. Taking such an approach to different areas of regulation can send a positive message that regulators are open and interested in the development of new ways of doing business and meeting the needs of the public. It has also been posited as sending a clear message to investors and innovators that it will be worthwhile to spend the time and effort it takes to create a new product or offer a new service,(85) especially if they are trying to implement "transformative ideas in a...system populated by entrenched incumbents". (50 p613) Using a sandbox approach could also be used to inform regulators about new technologies; if regulators understand new products and services, it becomes less likely that service providers can design their innovation "to avoid the letter (but violate the spirit) of regulations that aim to protect consumers".(50 p614-615)

However, some have also raised concern about adopting this model without first analyzing its effectiveness and without ensuring that society is not favouring regulatory expediency over fair play, competition, and public safety.(84) There is a particular concern raised in Canada over the recent amendments to the Food and Drugs Act that enabled the regulatory sandbox approach because "the formulation and implementation of the amendments...occurred with little opportunity for scrutiny or public engagement".(50 p2) The implications for regulators, clients, and society with respect to using this approach in a Canadian context may therefore not yet be fully understood or appreciated. 
It also must be remembered that the amendments that were made to the Food and Drugs Act were specific to drugs and devices, an area of healthcare overseen by Health Canada. The regulation of healthcare professionals is not similarly concentrated in one federal body; instead, there is a regulator in each province for each health profession. Since telehealth services could be provided by (or affect) numerous professionals within the system (such as doctors, nurse practitioners, registered nurses, dietitians, and alternative healthcare providers), each affected regulator would need to be engaged in the sandbox approach. The regulatory implications for physicians, for example, may or may not be identical to those for nurse practitioners or dietitians.

Another concern associated with the sandbox model is that it is premised on the regulator providing ongoing guidance to sandbox participants and ongoing monitoring of activities that take place within the sandbox. First, there is the possibility that this could amount to a redefinition of the role of a regulatory body to include facilitation of product and service development and innovation. Since there will always be a push-and-pull between facilitating innovation and access on the one hand, and ensuring the safety of health products and services on the other, it could be a significant concern to place both areas within the same regulatory mandate.(84) Second, there may be a very pragmatic concern of ensuring that a regulator actually has the resources available to provide the ongoing participation that such an approach entails. Healthcare regulators are often stretched significantly in their attempts to fill their public safety mandate and taking on such a resource-intensive initiative may simply not be feasible for smaller regulatory bodies.

\section{Future Considerations}

Even though regulatory sandboxes are increasingly being incorporated into many different types of societal relationships and in many different countries, little research has been conducted on the impact of using this model. It must be remembered that this is still a relatively new concept. Concerns have certainly been raised about sustainability of the approach, its applicability to settings in which it is being considered for use, and the wisdom of using the approach in so many different areas of society before it is better studied and understood. It is possible that more, distinctly Canadian policies or laws will need to be developed in the future to appropriately regulate this model. 


\section{CASE REPORT 2: For-profit Telehealth and Professional Regulation in Canada}

\section{Brief Overview}

For-profit telehealth has been expanding rapidly in Canada over the last few years with growth in availability and uptake spurred by the pandemic, as well as primary care physician shortages and the ease of accessing medical care via apps. For-profit telehealth occurs when corporations (like Telus, initially in partnership with Babylon) employ health professionals to provide care virtually via apps to the public. A few such corporations have partnered with provincial governments, with the latter picking up the costs of the services provided, including Telus (BC, Alberta, Ontario, Saskatchewan), Maple (Nova Scotia) and Lumeca (Saskatchewan). Through such arrangements, these private corporations generate profits via the public purse. Companies like Maple also provide services directly to consumers willing to pay out of pocket. This expansion of for-profit medical care within our not-for-profit healthcare system has brought new regulatory challenges and raised concerns on various fronts.

Concerns over the expansion of for-profit telehealth focus primarily on quality and continuity of care, given the episodic, on-demand nature of the care, often provided without access to client records or adequate follow-up. There have also been criticisms that the Al-powered symptom checkers used by the apps to provide medical information (which may be interpreted as a diagnosis by users) may be inaccurate, despite claims advanced by corporate sponsors that they are potentially more accurate than a doctor's diagnosis.(86) Other concerns raised include double-billing for services, and increased demands on the health system, as virtual care providers can diagnose or triage, but often must refer clients to others (sometimes emergency care in hospitals) for actual care. Both the app and the in-person provider then may end up billing for the same care. Equity is another concern, as younger people with fewer health problems have tended to be the main users of the app, while others may have less access. Regulation has not kept pace with the rapid changes in this area.

\section{History / Context}

For-profit, platform-mediated healthcare has been adopted in many regions of the world, including countries like the UK with public healthcare systems. In the UK, there is a commitment by the government to integrate for-profit healthcare into the existing public system. In Canada, Babylon partnered with Telus and launched their health app in BC in March of 2019. Telus is currently providing services through the app in several other provinces (in early 2021, Babylon sold its Canadian operations to Telus). As noted, several other Canadian provinces have entered into partnerships with for-profit providers. Some early challenges (like access to electronic medical records) are being resolved, but many regulatory issues remain.

\section{Regulatory Implications}

The sudden introduction and expansion of for-profit, platform-mediated telehealth has often preceded regulatory and social policy, creating regulatory gaps and grey areas. For example, 
when Telus partnered with the Alberta government and launched its services in the spring of 2020 , critics immediately raised concerns about privacy and data security, as well as inequities in billing: doctors working for the corporations could charge more than other doctors for the same services. New policies are being created to address these gaps.

Other areas of regulatory concern include the quality of services provided, continuity of care, discipline, and the potential for cross-border practice. With respect to discipline, for-profit care delivered through an app appears more impersonal. Will a client know who their care provider is? If there are problems with service provision, can (or will) clients report these problems to the regulator? Will the app or providers be held accountable for care recommendations given with insufficient information and no or limited access to clients' medical records? And what is fair in these circumstances? Will family physicians be notified when their patients seek care through the app, and if not, how will this impact their ability to provide quality care? Implications for quality of care, professional responsibility, liability, and accountability are significant.

Several regulators have recently, or are currently, revising their standards of practice around virtual care to address these concerns. The new policy in British Columbia requires that virtual care providers meet the same ethical, legal, professional, and quality standards as in-person providers, and this requires access to in-person care: "access to in-person care must be provided to patients as required and longitudinal care must be provided as indicated and required by patients".(87) Virtual care providers must enter into a "formal affiliation with inperson providers where the patient resides".(87) The new policy also requires that providers explicitly inform patients of their "name, location, and licensure status" and that they explain the "appropriateness, limitations, and privacy risks related to virtual care to the patient in plain language".(87) For-profit corporate telehealth is not currently set up to meet this standard in many contexts, but this standard is essential for quality care in the public interest.

For-profit telehealth also raises regulatory challenges for licensing. Currently, provinciallylicensed physicians are providing care to others in their province through the apps, but crossprovincial service provision is also possible, depending on licensing legislation. Some provinces allow cross-provincial practice, or have specific registration / licensing rules respecting telehealth, but others (such as Manitoba) are more restrictive. This is another area where regulatory reform is in progress.

Overall, this is such a new area, regulations and policies are still under development. Existing policies aim to cover both for-profit virtual care and not-for-profit care. Whether additional regulation is required for platform-mediated care is not entirely clear.

\section{Learnings from Other Jurisdictions}

The United Kingdom partnered with Babylon Health in 2017, at first on a trial basis. Here too there have been concerns raised about privacy, data security, the accuracy of the medical "advice" provided by app algorithms, the impact on local care provision, inequities in service 
load (as in-person providers deal with more complex, but not necessarily more remunerative cases), increased use of hospital emergency services for non-urgent care, and similar issues. Concerns have been raised about regulation - of the technology, data security, care usage, and professionals. Most of these issues remain unresolved.

In the United States, a telehealth regulator, Teladoc, sued the Texas Medical Board for mandating that consultations must be conducted face-to-face. This requirement was deemed a violation of anti-trust laws. Canadian standards tend to encourage in-person care, or virtual care in conjunction with in-person care when necessary. Canadian policies may also generate opposition from corporations in the coming months and years. More generally, for-profit care has been common in the United States, and these models of integrated care (such as those offered by Kaiser Health) may provide models to consider moving forward. The Canadian Medical Association wrote in 2019 that: "at the current rate of progress, it is likely to take decades for Canada to achieve the level of virtual care that is currently being delivered by systems such as Kaiser Permanente"(18, p16); the pandemic has, however, accelerated this progress to a degree. Regulation needs to keep pace with these changes.

\section{Future Considerations}

Provincial governments and professional regulators are finding ways to regulate for-profit, platform-mediated telehealth, but it is not clear that existing policies can protect the public interest in the face of expanding privatization. Al on the apps may be taken as providing diagnoses, despite corporations' claims that they are providing information only, and regulation of these Al-driven services appears limited. Platform-mediated work in other sectors has evaded, challenged, and altered current regulatory structures. More sweeping change, including how medical doctors are remunerated, may be necessary in the future, given the complexity of the issues at play.

Regulating in the public interest has long required balancing accessibility, safety, and quality, and the emergence of for-profit, virtual medical care has disrupted current frameworks, bringing new challenges for regulators. 


\section{CASE REPORT 3: Interjurisdictional Registration Pilot Project for Nurses in Two Canadian Provinces}

\section{Brief Overview}

The College and Association of Registered Nurses of Alberta (CARNA) and the Saskatchewan Registered Nurses Association (SRNA) are developing a memorandum of agreement (MOA) to facilitate cross provincial nursing practice. The project to establish a MOA to set a framework, budget and timeline for an interjurisdictional registration pilot project was presented at the June 25, 2021 Council meeting of the CARNA.(88) The two regulators have retained legal counsel to develop a series of options for interprovincial regulation that they expect to be under consideration by their respective executives over the summer of 2021 . The goal of the initiative is to 'reduce barriers to virtual services'. The matters to be resolved by the pilot project involve: establishment of requirements for interjurisdictional registration; agreement on ways to handle complaints and discipline; clarity over jurisprudence issues that affect care; agreement on billing; and clarity over provincial privacy issues.(88) Note that, at the time of writing, CARNA is in the process of separating its association and regulatory functions into separate bodies. The regulator will, as of late 2021, be known as the College of Registered Nurses of Alberta.

\section{History / Context}

CARNA reported that according to Alberta Health Services data, since 2017 there have been over 21,000 in-patient encounters and 356,000 outpatient services provided in Alberta to out-ofprovince recipients. Most of these services involved specialist services unavailable in the patient's province or territory. Currently, nurses are reluctant to be registered to practice in multiple jurisdictions due to prohibitive costs, complexity of application, and maintenance of practice requirements that are considered onerous (CARNA, 2021, Council livestream). CARNA believes the resultant lack of multi-jurisdictional registration poses a significant public safety risk. This situation has been exacerbated by the pandemic-led increase in virtual care.

\section{Regulatory Implications}

The CARNA/SRNA interjurisdictional project involves short-term and long-term strategies. The former focuses on mechanisms to enhance processes to support cross jurisdictional practice such as simplifying processes and reducing duplication and costs, the latter involves regulatory and legislative changes in both jurisdictions. The project is deemed a pilot as it is anticipated that it will expand across the western provinces with the potential to form the basis for a multijurisdictional national initiative. In addition to the pilot project forming the basis for an expanded project for western Canada, the CARNA and SRNA plan to coordinate IT developments that will form part of the project, with parallel developments at the national level to support multijurisdictional registration in Canada. One of these national initiatives is a parallel project, Nursys, which aims to establish a repository for registration and disciplinary data on registrants that is available to all Canadian nursing regulators and based upon the creation of a unique identifier for Canadian registered nurses and NPs.(89 p20) Nursys is collaboration between the College of Nurses of Ontario $(\mathrm{CNO})$ and the British Columbia College of Nurses 
and Midwives (BCCNM) to develop a Canadian version of the National Council of State Boards of Nursing centralized system that American regulators currently use to track nursing registrant data across the country. This Ontario/BC pilot will inform the working of the Canadian Multijurisdictional Working Group.(88 p21)

\section{Learnings from Other Jurisdictions}

The inter-provincial regulatory project has parallels to the licensure compact model of cross state regulation developed in multiple professions and industries in the United States. The Nurse Licensure Compact authorizes eligible nurses to practice across 35 member states while maintaining a single license. Taking a mutual recognition approach, the compact gives clarity on: eligibility (education, NCLEX, social security number); English proficiency; license status (unencumbered); biometric data check; and criminal history check. It also defines the relevant scope of practice and approach to disciplinary procedures.(90 p6-7) It is too early to say if the Canadian pilot is following the recommended pathway for American regulators in forming multi-state compacts as set out by the National Center for Interstate Compacts.(91 p3-5)

One key distinction between the American model and the proposed Canadian model is the rationale. For American regulators the value of a compact is that it enables mobility and supports the states to limit cross-state barriers through a model that enshrines state autonomy and minimizes federal jurisdiction over state matters. A study by the National Bureau of Economics conducted on the impact of compact membership on work patterns and mobility among nurses showed highly mobile nurses, which they defined as single nurses without children, had increased migration within compact states.(90 p6)The CARNA/SRNA pilot on the other hand is ostensibly focused on enabling virtual care and supporting the expansion of practice opportunities for registered nurses and nurse practitioners within a framework that ensures protection of the public through regulatory oversight. A minor point to note is that the original title of the project was Interjurisdictional Mobility Project, this was amended to Interjurisdictional Registration Project.(88) Despite this somewhat specific driver for regulatory reform and jurisdictional alignment and the absences of discussion of increased mobility as a possible outcome of multijurisdictional licensing, the CARNA/SRNA pilot is closely linked to other initiatives such as Nursys that are taking place under the auspices of the national working group on multijurisdictional registration.

\section{Future Considerations}

The MOA between Alberta and Saskatchewan RN and NP regulators is anticipated to be finalized over the summer of 2021 with an ambitious schedule for implementation of the pilot.(88 p100) The impact of the pilot on nursing practice in these two jurisdictions, its expansion to other western provinces and territories and its impact on the delivery of telemedicine by RNs and NPs in these jurisdictions should be closely monitored. Furthermore, the alignment of this project with the Nursys national identifier project for RNs and NPs points to several intersecting initiatives with the potential to change regulatory practices with respect to telemedicine and access to services, and nurse mobility in Canada. 


\section{CASE REPORT 4: The Essilor case: Competition, Disruptive Technology, and the Public Interest}

\section{Brief Overview}

Regulatory bodies are increasingly having to address the impact of disruptive technologies. This refers to the leveraging of technology to provide health care delivery/practice in a virtual or remote way (CNAR webinar). This can result in a disrupted delivery model, where health care practitioners may not even be present during the delivery of a health care service.

Virtual care is not new and over the last decade there has been increased reliance on virtual care.(18) However, the uptake of virtual care in Canada was accelerated by the COVID-19 pandemic. A study in Ontario found that a rise in virtual care was seen across the population, with a staggering increase from $1.6 \%$ of total ambulatory visits to $70.6 \%$ from the second quarter of 2019 to the second quarter of 2020.(93) This data is consistent with that coming out of the United States, where one study found that the update of virtual care increased from $4 \%$ prior to the pandemic to $35 \%$ during the pandemic.(93) The increased use of new and disruptive technologies will change how health care can be delivered, which will inevitably impact the expectations of patients regarding access to health care.(18)

\section{History / Context}

The regulation of health care providers and the services they provide to patients plays a critical role in ensuring quality and safety of health care. Fundamentally, regulation is used to "promote and protect the public interest".(59 p162) The current approach to regulation of health care providers in Canada has also been criticized for being protectionist, as it is often used to protect the "turf" of regulated professionals through over-regulation and rigid requirements.(59 pp172174) Virtual care made possible through technology highlights the challenges of discerning whether regulation is in the public's interest or the profession's.

Disruptive technologies pose particularly unique challenges for regulators when they provide for the delivery of care across traditional jurisdictional boundaries.(18) This is what was considered in College of Optometrists and Opticians v Essilor.(95) In this case, the Colleges sought an injunction to prevent what they considered to be the unauthorized practice of dispensing eyewear by Essilor's subsidiary, Clearly. In short, patients could order eyeglasses using their prescription from Clearly, which was situated in British Columbia, and have them delivered directly to their homes in Ontario without the supervision of an optometrist. The Colleges argued this was contrary to Ontario's Regulated Health Professionals Act.

The Ontario Court of Appeal held that there was not a sufficient connection to Ontario through the provision of eyewear, meaning the regulator did not have authority over Essilor, noting "the discrete act of delivering eyewear to a person primarily has a commercial aspect, not a health care one." Of importance to this decision is the fact that this approach was compliant with the regulations in British Columbia, where restrictions on the sale of corrective lenses did not require oversight by an optometrists or optician. The Court held, "[w]here the supplier of 
the prescriptions eyewear operates in another province and complies with that province's health professions regulatory regime ... the final act of delivering that product to the Ontario purchaser does not amount to the performance of a "controlled act" ..." (95 para 126)

\section{Regulatory Implications}

In response to the Essilor decision, commentators have noted that it will be more difficult to determine "when electronic, cross-border professional services can be restricted".(96) This is but one example of how disruptive technologies are forcing regulators to contend with how to regulate this space. What is clear from the Essilor decision is that the Ontario Court of Appeal was reluctant to grant Ontario optometrists and opticians a "monopoly".(95 para 127) The Court recognized that the Ontario Legislature, should it desire, could grant such a monopoly, but to do so would require that it "adopt language that clearly allows such a monopoly in order to comply with constitutional principle of territorial legislative restriction".(95 para 127) While the Essilor decision is context-specific and may not open the floodgates to aspects of virtual care or disruptive technologies that go beyond the delivery of a product, regulators may nevertheless be concerned that there are not sufficient safeguards to protect the public interest. After all, in Essilor patients were viewed as consumers, not patients, and the Court did not consider whether patients may be harmed if their eyewear was not properly fitted. Conversely, there are also concerns regulations may, in effect, operate to limit innovation and choice.

\section{Learning from Other Jurisdictions}

Other jurisdictions have grappled with the applicability of antitrust legislation to health care providers. In 2015, the Supreme Court of the United States determined in North Carolina State Board of Dental Examiners v Federal Trade Commission that licensing boards could only claim to be immune from federal antitrust actions if those boards were under active state supervision. In short, while licensing boards must protect public safety, they need to do so in a way that does not come across as anti-competitive.(97) To ensure this, the Federal Trade Commission has released guidance and numerous states have taken action to identify "innovative solutions that balance public safety with the promotion of a robust, competitive economy".(97)

\section{Future Considerations}

The Competition Bureau of Canada is currently examining the impact of registration and licensure on digital health care and the importance of a competitive market. In 2020, the Competition Bureau sought input on factors that might impede access to virtual care. It notes, "the Bureau aims to encourage the adoption of policies across Canada that achieve legitimate policy goals without inadvertently limiting the entry, expansion or consumer adoption of new products and services. This will help ensure that Canadians have access to innovative-and increasingly necessary — virtual health care solutions".(98) From this, the Bureau announced in April 2021 three broad topic areas, one of which is examining how health care providers can better deliver digital care.(99) It remains to be seen how regulators and the role of regulations on innovation and competition in digital health will be framed in the report due Spring 2022. 


\section{CASE REPORT 5: Legal Professionals' Duty of Technological Competence}

\section{Brief Overview}

When technology exists that can improve the quality and efficiency of professional services, and improve access to needed professional services, should a regulatory authority require that the professional use this technology to meet standards of competence? This has become a prominent issue in legal regulation in Canada and the United States. Historically, the concept of a lawyer's competence referred to a lawyer's knowledge of the law and ability to represent a client, but technology has rendered this interpretation outdated.(100) In response to this reality, a professional duty of technological competence has been added by many legal regulators in the United States and Canada, though the scope of this requirement remains vague.

\section{History / Context}

This duty was added in 2019 to the Federation of Law Societies of Canada's Model Code of Professional Conduct. The following commentary was added to the competence rule (3.1-2):

(4A): To maintain the required level of competence, a lawyer should develop an understanding of, and ability to use, technology relevant to the nature and area of the lawyer's practice and responsibilities. A lawyer should understand the benefits and risks associated with relevant technology, recognizing the lawyer's duty to protect confidential information set out in section 3.3. (4B) The required level of technological competence will depend on whether the use or understanding of technology is necessary to the nature and area of the lawyer's practice and responsibilities and whether the relevant technology is reasonably available to the lawyer. In determining whether technology is reasonably available, consideration should be given to factors including: (a) The lawyer's or law firm's practice areas; (b) The geographic locations of the lawyer's or firm's practice; and (c) The requirements of clients.

Salyzyn (2019) writes that the commentary to the Model Code in Canada embodies principles of proportionality by aiming to capture only technology that is "necessary to the nature and area of the lawyer's practice" and that is "reasonably available" to the lawyer.(82) At the time of writing, this duty of technological competence had been adopted by five Canadian jurisdictions.(101)

\section{Learnings from Other Jurisdictions}

The Canadian duty of technological competence in the Model Code of Professional Conduct mirrors the duty added earlier in the United States in 2012 to the American Bar Association's Model Rules of Professional Conduct (Comment 8 to Model Rule 1.1 on competence). As of the time of writing, the American version has been adopted by 39 states.(102) Commentators have been split between whether this is not a new requirement per se but rather a symbolic recognition of the importance of technology or instead is a new requirement to keep abreast of technological developments or face a heightened risk of regulatory disciplinary action.(39) While the wording was kept purposefully broad to encompass technologies in the future, there is little information on its current reach with individual regulators' guidance mainly discussing the duty in terms of electronic discovery, electronic information 
storage, social media, and the cloud.(100) The EU does not appear to have an equivalent duty.(103)

\section{Regulatory Implications}

Regulators for other professions should consider this duty of technological competence required by legal regulators in many Canadian and American jurisdictions for adoption in their own professions. This duty recognizes that traditional definitions of competence may be considered outdated in the face of technology that can demonstrably improve the quality and efficiency of services, and this may be true in many other regulated professions as well. Once adopted, regulators need to provide guidance to clearly articulate the rationale for (and ambit of) this duty and provide examples illustrating how these apply in practice and how the discipline regime will operate when technological incompetence is alleged.

\section{Future Considerations}

Regulators will need to grapple with emerging technologies in the provision of virtual care by their registrants. One area that needs to be evaluated is the role of the regulator in the use of $\mathrm{Al}$ by professionals. Medianik (2018) notes that despite the adoption of the duty of technological competence by many states "there are currently no standards in place about what it means to be a prudent or competent lawyer in relation to Al usage" (69 p1515) and efforts states have made so far "remain too ambiguous to lend an adequate sense of direction for lawyers using Al technology."(69 p1515) Baker also argues that as society moves beyond the Information Age to the Algorithmic Society, the regulatory duty of technological competence should extend to the legal professional's competent use of Al and algorithms in law.

There is a role for professional regulation when $\mathrm{Al}$ is used by registrants to supplement or replace elements of their professional work because there is an increased vulnerability for consumers given Al's capacity for autonomous action, inability to foresee outcomes or assess performance, and lack of transparency.(39) Haupt (2019) concluded that professional discipline of $\mathrm{Al}$ is not relevant since, unlike humans, $\mathrm{Al}$ cannot conform its behaviour to the relevant standards of practice on the threat of professional discipline.(105) Thus, Haupt (2019) argued that it is necessary for regulators to take steps to ensure that the regulated professionals using Al are competent to do so.(105) Medianik (2018) also argued that the better option is to regulate the human professional using the $\mathrm{Al}$ rather than the $\mathrm{Al}$ agent itself.(104)

Regulators should not justify leaving new technology to existing regulatory regimes due to a lack of information about the technology's likely impact; instead, regulators should provide clear and certain information so lawyers understand how their use of Al will be governed.(39) Qarri (2021) adds that while lawyers must adopt technologies that are essential to the competent representation of their clients, it is functionally unrealistic to demand Al expertise from lawyers and thus the responsibility shifts to the professional regulator to provide regulation around the use of predictive $\mathrm{Al}$ in legal practice in a realistic manner.(103) 


\section{Research Strengths and Gaps}

We used a comprehensive and systematic approach to our knowledge synthesis and now have a foundational base on how the public interest is conceptualized when regulating professionals providing virtual services. While the focus of a scoping review is to provide breadth rather than depth, we included the case examples to take a deeper dive on some of the issues raised in the scoping review.

Much of the literature was descriptive case examples, critical commentaries, or legal analysis rather than scientifically based evaluative research. Almost all articles focused on health professions. This potentially points to limitations of our search strategy though it is likely that virtual practice in the health professions is the most studied. Regulatory research focused on virtual professional practice should be further developed and expanded to occupations outside of health.

The terminology used across these articles varied and other regulated professions may use terms not considered in this review to describe aspects of regulating virtual practice. Few of the articles we reviewed focused specifically on the public interest, highlighting a need to further examine how the public interest is conceptualized when regulating virtual practice.

Given that most professional regulators have individual guidelines around virtual practice, we could not feasibly include these as sources given the sheer number of sources this would have included. Also, given how virtual professional practice is rapidly changing, we only included sources since 2015. Evidence from further grey literature, including regulatory documents, or from earlier studies may have informed this review had we included them.

Given the timeline for this knowledge synthesis, we were not able to engage stakeholders for feedback on our search strategy or findings. We have received a SSHRC Insight Development Grant (2021-2023) to build on this knowledge synthesis and plan to include stakeholder engagement throughout that study. 


\section{Implications for Policy and Practice}

The concept of the public interest continues to evolve in relation to virtual practice: Professional regulation must act in the public interest, but how the public interest is defined is amorphous and subject to social change. The emergence of the digital economy and the rapid shift to virtual service provision seen during the COVID-19 pandemic accelerated some of this evolution, with a shift from justifying virtual professional service provision to justifying any need for in-person requirements. The public interest is not just about quality service, as accessibility and affordability are also in the interests of the public: As MacKenzie (2021) notes, ensuring quality services is of little use if the public cannot access them. Our review shows a focus in the academic literature on balancing public safety with equitable access to services and economic competitiveness to determine the public interest.(106) This focus may continue to shift as we move into a post-pandemic world.

\section{Professional regulators have an important role in adapting to new technologies that impact professional practice and providing clear standards and guidelines around virtual practice: Regulators can provide clear standards and guidelines for professionals on their use of certain technologies in practice. This needs to include what is required for competent practice since traditional definitions of competence and quality may be outdated in the era of virtual service provision. Professional regulators have a role in regulating technology (or the use of it) but this regulation may require a new regulatory design that focuses less on individual professionals and more on desired outcomes (117).}

\section{Governments and regulators need to consider how to facilitate virtual services across} jurisdictional borders: Critical to regulating virtual practice is the issue of cross-jurisdictional practice. Regulation at the subnational level (state/provincial/territorial) emerged historically to regulate providers providing in-person services locally; however, in the context of virtual service provision, this no longer holds true. The highly variable geographic approach to licensure and registration has become increasingly problematic and difficult to defend. To leverage virtual care to its fullest extent in both steady state and future global public health threats, it is important for governments to work with regulators to standardize the regulation of virtual care.

\section{Professional regulators need to grapple with pressing and emerging virtual practice} issues: Al-enabled practice, for-profit telehealth, and disruptive technologies were all raised in this review as having regulatory implications but remaining unresolved. As the Law Society of BC's Futures Task Force wrote: "it would be contrary to the public interest in the administration of justice for the Law Society not to identify the importance of adopting technology in the profession in ways that serve the public interest." $(117, \mathrm{p} 12)$. The idea of a regulatory sandbox for innovative technologies should be considered in professions outside of finance and law, including in the health and social care professions. 


\section{Future Research Areas}

Our report has highlighted knowledge gaps around how professional regulators can act in the public interest when regulating practitioners who provide virtual or digitally-enabled services.

- In our review, there was a clear focus in the academic literature on health and social care professions, highlighting a need to examine learnings from other professions as well.

- Most of the articles were reviews or commentaries, and there is little empirical evidence on which to base regulatory activities around virtual practice or to understand the impact of regulation on equitable access to and affordability of virtual professional services.

- The literature did not always touch on the public interest explicitly; hence there is a need for more research on the public interest in regulating virtual practice in Canada.

- There is a need to understand how the public can best be engaged in the regulatory process, particularly around understanding the public interest when receiving virtual professional services and how this should translate into regulatory policies and practices. Reforms in recent years have included more inclusive and expansive participation of the public in regulation $(118,119)$. Public engagement with regulation around particular technologies may influence regulators to understand what initial assumptions made about impact, harm, and risk may have been false and allow for continual evaluation and adjustment (20).

- Many of the articles focused on the virtual practice regulatory changes necessitated by the COVID-19 pandemic. It will be very important to continue to monitor and evaluate professional regulation through research to determine the continued value of these changes in the post-pandemic world.

- Virtual professional services have the potential to improve quality and equity of services but may introduce new areas of potential risk and amplify existing inequalities, particularly with the digital divide that exists along socioeconomic lines (48). Future research should consider this lens on regulatory initiatives in the public interest. 


\section{Knowledge Mobilization}

Our key knowledge mobilization activities include the following:

- This report will be presented to stakeholders at the virtual knowledge mobilization forum for the Skills and Work in the Digital Economy knowledge synthesis grants in September 2021.

- The evidence brief accompanying this report, as well as the full report, will be posted online and distributed by social media and/or email to the research teams' networks.

- We registered the scoping review protocol with the Open Science Framework (10.17605/OSF.IO/BD2ZX) and submitted the protocol for publication that is under review.

- We submitted an abstract to present this research at the IEEE International Symposium on Technology and Society in October 2021.

- We will prepare other papers from this report and submit for open access publication.

- Our research team received a SSHRC Insight Development Grant for a project entitled Professional Regulation in the Digital Era: Modernizing Regulatory Practices in the Public Interest (2021-2023) that will build on this knowledge synthesis. 


\section{References}

1. Nurse Advisory Group [Internet]. College of Nurses of Ontario. 2021 [cited 2021 Jan 12]. Available from: https://www.cno.org/en/learn-about- standards-guidelines/get-involved/nurse-advisory-group/

2. LSO COVID-19 response: Commissioning and notarization [Internet]. Law Society of Ontario. [cited 2021 Jan 12]. Available from: https://lso.ca/covid-19-response/faqs/practice-management\#can-a-lawyer-or-paralegal-use- remoteorvirtual-commissioning--5

3. Clamp A. Professional regulation and registration will need to be flexible to respond to the Covid-19 emergency [Internet]. Professional Standards Authority for Health and Societal Care Insights into Regulation Blog. 2020 [cited 2021 Jan 12]. Available from: . https://www.professionalstandards.org.uk/news-andblog/ $\mathrm{blog} / \mathrm{detail} / \mathrm{blog} / 2020 / 04 / 08 /$ professional-regulation-and-registration-will-need-to-be- flexibleto-respond-to-the-covid19-emergency

4. Biggar M, Lobigs L, Fletcher M, Man M. How can we make health regulation more humane? A quality improvement approach to understanding complainant and practitioner experiences. J Med Regul. 2020;106(1).

5. Gunderson W, Zhang T, Gomez R. Relaxing restrictions on occupational licensing as a response to COVID-19 [Internet]. Canadian Law of Work Forum. 2020 [cited 2021 Jan 14]. Available from: http://lawofwork.ca/relaxingrestrictions-onoccupational-licensing-as-a-response-to-covid-19/.

6. Fraher E, Pittman P, Frogner B, Spetz J, Moore J, Beck A, et al. Perspective: Ensuring and sustaining a pandemic workforce. N Engl J Med. 2020;(382):2181-3.

7. Rhoads J. Silver linings in state responses to COVID-19 [Internet]. The Objective Standard. 2020 [cited 2021 Jan 14]. Available from: https://www.theobjectivestandard.com/2020/04/silver-linings-in-state-responses-to-covid- 19/ 8. Flood J. The re-landscaping of the legal profession: Large law firms and professional re- regulation. Curr Sociol. 2011;59(4):507-29.

9. Hadfield G, Rhode D. How to regulate legal services to promote access, innovation, and the quality of lawyering. Hastings Law Journal. 2016;67:1192-224.

10. Devlin R, Heffernan P. The end(s) of self regulation? 2008;45(5):169-214.

11. Van Sickle C. . Practice notes: Professional and ethical: Communication technology practices and policies for a digital world [Internet]. Ontario College of Social Workers and Social Service Workers. 2014 [cited 2021 Jan 8].

Available from: ocswssw.org

12. U.S. states and territories modifying requirements for telehealth in response to COVID-19 [Internet]. Federation of States Medical Boards. 2020 [cited 2021 Jan 8]. Available from: https://www.fsmb.org/siteassets/advocacy/pdf/stateemergency-declarations-licensures-requirementscovid-19.pdf

13. Pharmascience Inc v Binet. Vol. 2, 513. 2006.

14. Law Society of New Brunswick v Ryan. Vol. 1, 247. 2003.

15. Mercer M. Thoughts about self-regulation in the public interest [Internet]. SLAW. 2019 [cited 2021 Jan 6].

Available from: http://www.slaw.ca/2019/11/05/thoughts-about-self-regulation-in-the- public-interest/.

16. Benton DC, Cleghorn J, Coghlan A, Damgaard G, Doumit M, George J, et al. Acting in the public interest: Learnings and commentary on the occupational licensure literature. J Nurs Regul. 10(2):1-40.

17. Virtual dietetic practice update in the age of COVID-19 [Internet]. College of Dietitians of British Columbia. 2020 [cited 2021 Jan 8]. Available from: https://collegeofdietitiansofbc.org/virtual-dietetic-practice-covid19/

18. CMA health summit: Virtual care in Canada discussion paper. Canadian Medical Association. [Internet]. 2019 [cited 2021 Jan 10]. Available from:

https://www.cma.ca/sites/default/files/pdf/News/Virtual_Care_discussionpaper_v2EN.pdf

19. Framework on telemedicine [Internet]. Federation of Medical Regulatory Authorities of Canada. 2018. Available from: https://fmrac.ca/wp-content/uploads/2019/04/Framework-on-Telemedicine-Final.pdf

20. Bennett Moses L. Regulating in the Face of Sociotechnical Change. In: The Oxford Handbook of Law, Regulation and Technology. United Kingdom: Oxford University Press; 2017.

21. Amara N, landry R, Doloreux D. Patterns of innovation in knowledge intensive business services. Service Industries Journal. 29(4):407-30.

22. Boussebaa M, Morgan G. Internationalization of Professional Service Firms. In: Oxford Handbook of Professional Service Firms. Oxford, United Kingdom: Oxford University Press; 2015. p. 51-71.

23. Hinings B, Gegenhuber T, Greenwood R. Digital innovation and transformation: An institutional perspective. Information and Organization. 2018;28(1):52-61. 
24. Armour J, Sako M. Al-enabled business models in legal services: From traditional law firms to next-generation law companies? Journal of Professions and Organization. 2020;7(1):27-46.

25. Kronblad C. How digitalization changes our understanding of professional service firms. 2020;6(3):436-54.

26. LSO COVID-19 response: Wills and power of attorney [Internet]. Law Society of Ontario. 2020 [cited 2021 Jan 12]. Available from: https://lso.ca/covid-19-response/faqs/practice-management\#is-remote-execution-and- witnessingofwills-and-powers-of-attorney-permitted-in-the-context-of-covid-5

27.LSO COVID-19 response: Client identification and verification [Internet]. Law Society of Ontario. 2020 [cited 2021 Jan 12]. Available from: https://lso.ca/covid-19-response/faqs/practice-management\#in-the-context-of-covid-19-canalawyer-or-paralegal-use-a-virtual-means-of-identifying-or-verifyin-5

28. Moher D, Liberati A, Tetzlaff J, Altman D. Preferred reporting Items for systematic reviews and meta-analyses: The PRISMA statement. PLoS Med.

29. What is telehealth? [Internet]. The Center for Connected Health Policy. Available from:

https://www.cchpca.org/what-is-telehealth/

30.Vance GA. The Hoosiers Got It Wrong: The Need for States to Enact Stricter Prescribing Regulations via

Telemedicine Services Notes. Wm Mary Bus Rev. 2020;12(1):221-46.

31. Nelson K. "To Infinity and Beyond": A Limitless Approach to Telemedicine Beyond State Borders. Brooklyn Law

Rev [Internet]. 2020;85(3). Available from: https://brooklynworks.brooklaw.edu/blr/vol85/iss3/11

32. Webb C, Orwig J. Expanding our Reach: Telehealth and Licensure Implications for Psychologists. J Clin Psychol Med Settings. 2015;22(4):243-50.

33. Harris B, Birnbaum R. Ethical and Legal Implications on the Use of Technology in Counselling. Clin Soc Work J. 2015;43(2):133-41.

34. Fields BG. Regulatory, Legal, and Ethical Considerations of Telemedicine. Sleep Med Clin. 2020;15(3):409-16.

35.Lacktman N, Ferrante T. Congress Proposes Change to Ryan Haight Act to Allow Telemedicine Prescribing of

Con- trolled Substances [Internet]. Foley \& Lardner LLP. 2018. Available from:

https://www.foley.com/en/insights/publications/2018/03/congress-proposes-change-to-ryan-haight-act-to-all

36. Chandwani R, Dwivedi Y. Telemedicine in India: Current state, challenges and opportunities. Transform Gov

People Process Policy. 2015;9(4):393-400.

37. Nittari G, Khuman R, Baldoni S, Pallotta G, Battineni G, Sirignano A, et al. Telemedicine Practice: Review of the Current Ethical and Legal Challenges. Telemed J E-Health Off J Am Telemed Assoc. 2020;26(12):1427-37.

38. Adashi EY, Cohen IG, McCormick WL. The Interstate Medical Licensure Compact: Attending to the Underserved. JAMA. 2021;325(16):1607-8.

39. Rogers J, Bell F. The Ethical Al Lawyer: What is Required of Lawyers When They Use Automated Systems? Law Technol Hum. 2019 Nov 25;80-99.

40. Cross-border physiotherapy within Canada [Internet]. Canadian Alliance of Physiotherapy regulators. 2019.

Available from: https://www.alliancept.org/licensure/cross-border-physiotherapy-within-

canada/\#: :text=On\%20May\%2011\%2C\%202017\%2C\%20a,access\%20to\%20care\%20within\%20Canada.\&text=Nin ety $\% 2$ Dfive $\% 20$ percent $\% 20$ of $\% 20$ the,only $\% 208 \% 25 \% 20$ of $\% 20$ registered $\% 20$ physiotherapists.

41. CADTH Brief: Inter-jurisdictional Medical Licensing to Support Telemedicine [Internet]. The Canadian Agency for Drugs and Technologies in Health. 2020. Available from: https://cadth.ca/sites/default/files/hta-he/cadth-policy-briefinterjurisdictional-licensing-final.pdf

42. Shafer M. New compacts announced [Internet]. National Center for Interstate Compacts. Available from:

https://compacts.csg.org/march-15-2021-new-compacts-announced/

43. Licensure compacts [Internet]. The Center for Connected Health Policy. Available from:

https://www.cchpca.org/topic/licensure-compacts/

44. Wicklund E. New telehealth bill would penalize states who don't join licensure compact [Internet]. Available from: https://mhealthintelligence.com/news/new-telehealth-bill-would-penalize-states-who-dont-join-licensure-compact 45. Segal EM, Alwan L, Taketa C, Indorf A, Held L, Lee KS, et al. Establishing clinical pharmacist telehealth services during the COVID-19 pandemic. Am J Health Syst Pharm. 2020;77(17):1403-8.

46. Parrott CM. Talking Telemedicine and Terminology: The South Carolina Telemedicine Act Health Law. C Rev. 2016;68(4):665-88.

47. Cortelyou-Ward K, Atkins DN, Noblin A, Rotarius T, White P, Carey C. Navigating the Digital Divide: Barriers to Telehealth in Rural Areas. J Health Care Poor Underserved. 2020;31(4):1546-56.

48. Hashiguchi T. Bringing health care to the patient: An overview of the use of telemedicine in OECD countries.

2020;116. 
49. McKean AJ, Gentry MT, Cowan KE, Hilty DM. Barriers to Use of Telepsychiatry: Clinicians as Gatekeepers. Mayo Clin Proc. 2019;94(12):2510-23.

50. Kramer GM, Kinn JT, Mishkind MC. Legal, Regulatory, and Risk Management Issues in the Use of Technology to Deliver Mental Health Care. Cogn Behav Pract. 2015;22(3):258-68.

51. Gajarawala SN, Pelkowski JN. Telehealth Benefits and Barriers. J Nurse Pract. 2021;17(2):218-21.

52. Kinoshita S, Cortright K, Crawford A, Mizuno Y, Yoshida K, Hilty D, et al. Changes in telepsychiatry regulations during the COVID-19 pandemic: 17 countries and regions' approaches to an evolving healthcare landscape. Psychol Med. 2020;(qer, 1254142):1-8.

53. Uscher-Pines L, Mulcahy A, Cowling D, Hunter G, Burns R, Mehrotra M. Access and quality of care in direct-toconsumer telemedicine. Telemed J E Health. 22(4):282-7.

54. Sklar T, Robertson CT. Telehealth for an Aging Population: How Can Law Influence Adoption Among Providers, Payors, and Patients?. Am J Law Med. 2020;46(2-3):311-24.

55. Shigekawa E, Fix M, Corbett G, Roby DH, Coffman J. The current state Of telehealth evidence: A rapid review. Health Aff (Millwood). 2018;37(12):1975-82.

56. Tackes P. Going Online with Telemedicine: What Barriers Exist and How Might They Be Resolved. Okla JL Tech. 2015;11:1-37.

57. Yang YT, Kozhimannil KB. Medication Abortion Through Telemedicine: Implications of a Ruling by the lowa Supreme Court. Obstet Gynecol. 2016;127(2):313-6.

58. Guilbert E, Costescu D, Wagner M-S, Renner R, Norman W, Dunn S, et al. Canadian protocol for the provision of medical abortion via telemedicine [Internet]. The Society of Obstetricians and Gynecologists of Canada. 2020 [cited 2021 Jan 8]. Available from:

https://www.sogc.org/common/Uploaded\%20files/CANADIAN\%20PROTOCOL\%20FOR\%20THE\%20PROVISION\%2 0OF\%20MA\%20VIA\%20TELEMEDICINE.pdf

59. Chandrashekar $\mathrm{P}$, Jain SH. Eliminating barriers to virtual care: implementing portable medical licensure. Am J Manag Care. 2020;26(1):20-2.

60. Dvorak K. State licensure problems plague telemedicine [Internet]. FIERCE Healthcare. Available from: https://www.fiercehealthcare.com/it/state-licensure-problems-plague-telemedicine

61. Svorny S. Liberating telemedicine: Options to eliminate the state-licensing roadblock [Internet]. CATO Institute.

2017. Available from: https://www.cato.org/policy-analysis/liberating-telemedicine-options-eliminate-state-licensingroadblock

62. Maskalyk J. Petition to the Minister of Health [Internet]. House of Commons: Petitions. 2021. Available from: https://petitions.ourcommons.ca/en/Petition/Details?Petition=e-3378

63. Advancing a dialogue towards pan Canadian Licensure and Registration of Health Professionals [Internet].

Canadian Institutes of Health Research. 2019. Available from: https://cihr-irsc.gc.ca/e/51804.html

64.Regulated Health Professions Act. 1991.

65. Government of Canada announces new independent regulator for patent and trademark agents [Internet]. Government of Canada. 2021. Available from: https://www.canada.ca/en/innovation-science-economic-

development/news/2021/06/government-of-canada-announces-new-independent-regulator-for-patent-and-trademarkagents.html

66. How CPATA works - Its principled approach to regulation and governance [Internet]. College of Patent and

Trademark Agents Act. 2021. Available from: https://cpata-cabamc.ca/wp-content/uploads/2021/06/2021-04-05-

Board-Policy-No-1-How-CPATA-works.pdf

67. U.S. states and territories modifying requirements for telehealth in response to COVID-19 [Internet]. Federation of States Medical Boards. 2021. Available from: https://www.fsmb.org/siteassets/advocacy/pdf/states-waiving-licensurerequirements-for-telehealth-in-response-to-covid-19.pdf

68. Wolf TD. Telemedicine and Malpractice: Creating Uniformity at the National Level Notes. Wm Mary Rev.

2019;61(5):[i]-1536.

69. Mullangi S, Agrawal M, Schulman K. The COVID-19 Pandemic - An Opportune Time to Update Medical Licensing. JAMA Intern Med. 2021;181(3):307-8.

70. Mehrotra A, Nimgaonkar A, Richman B. Telemedicine and Medical Licensure - Potential Paths for Reform. N Engl J Med. 2021;384(8):687-90.

71. Rogove H, Stetina K. Practice challenges of intensive care unit telemedicine. Crit Care Clin. 2015;31(2):319-34. 
72. Simon L, Friedland B. Interstate Practice of Dental Teleradiology in the United States: The Effect of Licensing Requirements on Oral and Maxillofacial Radiologists' Practice Patterns. Telemed J E-Health Off J Am Telemed Assoc. 2016;22(6):541-5.

73. Marcoux RM, Vogenberg FR. Telehealth: Applications From a Legal and Regulatory Perspective. P T Peer-Rev J Formul Manag. 2016;41(9):567-70.

74. National registration and accreditation scheme [Internet]. Australian Government Department of Health. 2021. Available from: https://www.health.gov.au/initiatives-and-programs/national-registration-and-accreditation-scheme 75. Cardoso AL, Rendeiro MM, C.S Queiróz, Souza FN, Lindenblatt RCR. Training and work of dental surgeons in the European Union. Revista da ABENO. 20(1):102-12.

76. Bhatia A, Matthan R, Khanna T, Balsari S. Regulatory sandboxes: A cure for mHealth pilotitis? J Med Internet Res. 2020;22(9).

77. Walsh C. Regulatory Sandbox: A New Tool for Telehealth Innovation in a Post-Covid World [Internet]. Columbia Business Law Review. 2021. Available from:

https://journals.library.columbia.edu/index.php/CBLR/announcement/view/406

78. Leckenby E, Dawoud, Bouvy J, Jónsson P. The sandbox approach and its potential for use in health technology assessment: A literature review. Applied Health Economics and Health Policy [Internet]. 2021; Available from: https://ink.springer.com/article/10.1007/s40258-021-00665-1

79. Regulatory Sandboxes in Data Protection: Constructive Engagement and Innovative Regulation in Practice [Internet]. Centre for information Policy Leadership. 2019. Available from:

https://www.informationpolicycentre.com/uploads/5/7/1/0/57104281/cipl_white_paper_on_regulatory_sandboxes_in_d ata_protection_-_constructive_engagement_and_innovative_regulation_in_practice_8_march_2019_.pdf

80. Allen H. Regulatory sandboxes. The George Washington Law Review. 2019;87(3):579-645.

81. Furlong J. The paradigm shift of regulatory sandboxes [Internet]. Slaw. 2020. Available from:

http://www.slaw.ca/2020/12/17/the-paradigm-shift-of-regulatory-sandboxes/

82.Salyzyn A. It's finally (sort of) here!: A duty of technological competence for Canadian lawyers [Internet]. SLAW.

2019. Available from: http://www.slaw.ca/2019/11/26/its-finally-sort-of-here-a-duty-of-technological-competence-for-

canadian-lawyers/

83. Regulatory innovation for health products: Enabling advanced therapeutic products [Internet]. Government of

Canada. 2021. Available from: https://www.canada.ca/en/health-canada/corporate/about-health-canada/activities-

responsibilities/strategies-initiatives/health-products-food-regulatory-modernization/advanced-therapeutic-

products.html

84. Vural IE, Herder M, Graham JE. ). From sandbox to pandemic: Agile reform of Canadian drug regulation. Health

Policy [Internet]. 2021; Available from:

https://www.sciencedirect.com/science/article/pii/S0168851021001160?via\%3Dihub

85. Smith D. Law Society of Ontario approves regulatory sandbox for legal tech [Internet]. National Magazine. 2021.

Available from: https://www.nationalmagazine.ca/en-ca/articles/legal-market/regulatory/2021/law-society-of-ontarioapproves-regulatory-sandbox

86. Burkhi T. GP at hand: a digital revolution for health care provision? Lancet. 2019;394(10197):457-60.

87. Practice standard: Virtual care [Internet]. College of Physcians and Surgeons of British Columbia. 2021. Available from: https://www.cpsbc.ca/files/pdf/PSG-Virtual-Care.pdf

88. CARNA council meeting. College and Association of Registered Nurses of Alberta. 2021.

89. NPAC-AlIPC March e-Newsletter [Internet]. Nurse Practitioner Association of Canada-Association des Infirmières

Praticiennes du Canada. 2021. Available from: https://npac-aiipc.org/newsletters/march-2021-newsletter/

90. March e-Newsletter. [Internet]. Nurse Practitioner Association of Canada-Association des Infirmières Praticiennes

du Canada. 2021. Available from: https://npac-aiipc.org/newsletters/march-2021-newsletter/

91. Occupational licensure and interstate compacts in action. [Internet]. Council of State Governments. 2019.

Available from: https://licensing.csg.org/wp-content/uploads/2019/07/OccpationallnterstateCompacts-

InAction_Web.pdf

92. National Center for Interstate Compacts [Internet]. Multistate Problem Solving with Interstate Compacts. 2019.

Available from: https://licensing.csg.org/wp-content/uploads/2019/04/Compact-Resource-Guide-1.pdf

93. Alexander G, Tajanlangit M, Heyward J, Mansour O, Qato DM, Stafford RS. Use and content of primary care

office-based vs telemedicine care visits during the COVID-19 pandemic in the US. JAMA Netw Open. 2020;3(10).

94. Zarzeczny A. The Role of Regulation in Health Care - Professional and Institutional Oversight. In: Canadian

Health Law and Policy 5th ed. Toronto: LexisNexis; 2017. 
95. College of Optometrists and Opticians v Essilor. 2019.

96. Leblanc B. Telepractice rules become more complicated [Internet]. SML Law. 2019. Available from:

https://www.sml-law.com/wp-content/uploads/2019/04/Greyar235.pdf

97. Occupational licensing final report: assessing state policies and practices [Internet]. National Conference of State Legislatures. 2020. Available from: https://www.ncsl.org/research/labor-and-employment/occupational-licensing-finalreport-assessing-state-policies-and-practices637425196.aspx

98. Canada's health care sector: have a say on how to support innovation and choice [Internet]. Government of Canada. 2020. Available from: https://www.canada.ca/en/competition-bureau/news/2020/07/canadas-health-caresector-have-a-say-on-how-to-support-innovation-and-choice.html 99. Government of Canada [Internet]. Market Study Notice: Digital Health Care. 2021. Available from: https://www.competitionbureau.gc.ca/eic/site/cb-bc.nsf/eng/04579.html 100. Baker JJ. Beyond the Information Age: The duty of technology competence in the Algorithmic Society. S C Law Rev. 2018;69:557-77.

101. Interactive Model Code of Professional Conduct [Internet]. Federation of Law Societies of Canada. [cited 2021 Jul 23]. Available from: https://flsc.ca/interactivecode/

102. Tech competence: 39 states have adopted the duty of technology competence. Law Sites.

103. Qarri A. Trust no Al? : Updating the duty of competence for the modern lawyer [Internet]. SLAW. 2021. Available from: http://www.slaw.ca/2021/02/01/trust-no-ai-updating-the-duty-of-competence-for-the-modern-lawyer/

104. Medianik K. Artificially intelligent lawyers: Updating the Model Rules of Professional Conduct in accordance with the new technological era. Cardozo Law Rev. 2018;39(4):1497-530.

105. Haupt CE. Governing A.I.'s Professional Advice. McGill Law J. 2019;64(4):665.

106. MacKenzie B. Why do we regulate lawyers? [Internet]. SLAW. 2021. Available from:

http://www.slaw.ca/2021/01/14/why-do-we-regulate-lawyers/?utm_medium=twitter\&utm_source=dlvr.it\#_ftn2

107. Silva AB, da Silva RM, Ribeiro G da R, Guedes ACCM, Santos DL, Nepomuceno CC, et al. Three decades of telemedicine in Brazil: Mapping the regulatory framework from 1990 to 2018. PloS One. 2020;15(11):e0242869.

108. What is Telemedicine? [Internet]. Chiron Health. 2021. Available from:

https://chironhealth.com/telemedicine/what-is-\%20telemedicine/

109. Park J, Erikson C, Han X, lyer P. Are state telehealth policies associated with the use of telehealth services among underserved populations? Health Aff (Millwood). 2018;37(12):2060-8.

110. Kwong MW, Calouro CY, Nasseir LM. Telehealth private payer laws: Impact and issues [Internet]. The Center for Connected Health Policy. 2017. Available from: https://www.milbank.org/wp-content/uploads/2017/08/MMF-

Telehealth-Report-FINAL.pdf

111. Rambur B, Palumbo MV, Nurkanovic M. Prevalence of Telehealth in Nursing: Implications for Regulation and Education in the Era of Value-Based Care. Policy Polit Nurs Pract. 2019;20(2):64-73.

112. Model policy for the appropriate use of telemedicine technologies in the practice of medicine [Internet].

Federation of State Medical Boards. 2014. Available from:

https://www.fsmb.org/siteassets/advocacy/policies/fsmb_telemedicine_policy.pdf

113. Shaw J, Jamieson T, Agarwal P, Griffin B, Wong I, Bhatia SR. Virtual care policy recommendations for patient-

centred primary care: findings of a consensus policy dialogue using a nominal group technique. J Telemed Telecare. 2018;24(9):608-15.

114. Virtual care: Recommendations for scaling up virtual medical services [Internet]. Canadian Medical Association. 2021. Available from: https://www.cma.ca/virtual-care-recommendations-scaling-virtual-medical-services

115. Lougheed T. Time to embrace the promise of virtual health care. CMAJ. 2019;191(11):E320-1.

116. Wong A, Lomax LB, Appireddy R, Bhyat R, Srivastava S. Patient Care during the COVID-19 Pandemic:Use of Virtual Care. J Med Internet Res. 2021;23(1):20621.

117. Anticipating Changes in the Delivery of Legal Services and the Legal Profession: The Final Report of the Futures Task Force [Internet]. Law Society of British Columbia. 2021 [cited 2 August 2021]. Available from: https://www.lawsociety.bc.ca/Website/media/Shared/docs/initiatives/2020FuturesTaskForceReport.pdf

118. Leslie K, Nelson S, Deber R, Gilmour J. Policy Tensions in Regulatory Reform: Changes to Regulation of Health Professions in Australia, the United Kingdom, and Ontario, Canada. Journal of Nursing Regulation. 2018;8(4):32-42. 119. Adams, T.L. Health professional regulation in historical context: Canada, the USA and the UK (19th century to present). Hum Resour Health 18, 72 (2020). https://doi.org/10.1186/s12960-020-00501-y 


\section{Appendix A: Search Strategy}

Search strategy for MEDLINE via Ovid conducted on 29 May 2021.

\begin{tabular}{|c|c|c|}
\hline Search & Query & $\begin{array}{l}\text { Records } \\
\text { Retrieved }\end{array}$ \\
\hline 1 & $\begin{array}{l}\text { exp telemedicine/ or internet-based intervention/ or ((videoconferencing/ } \\
\text { or electronic mail/ or exp cell phone/ or exp internet/ or telephone/ or } \\
\text { mobile applications/) and (exp patient care management/ or exp patient } \\
\text { care/)) }\end{array}$ & 49381 \\
\hline 2 & $\begin{array}{l}\text { (telehealth or telecaring or telecare or telemedicine or telenurs* or } \\
\text { telerehab* or teleconsult* or mhealth or ehealth or mobile health or } \\
\text { telepathol } \text { or teleradiol* or telemonitor }^{*} \text { or tele monitor }{ }^{*} \text { or telediagnos* } \\
\text { or telepsych }^{*} \text { or erehab* or telesurger* or teletherap* or "m health" or "e } \\
\text { health" or teleconferenc }{ }^{*} \text { or telecounsel }{ }^{*} \text { ).ti,ab,kf }\end{array}$ & 43700 \\
\hline 3 & 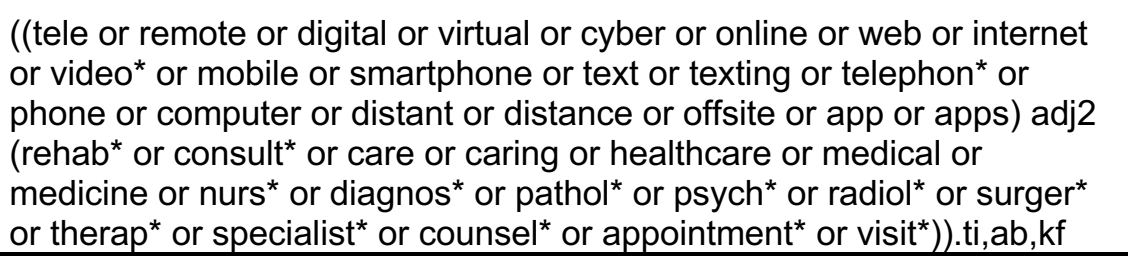 & 49552 \\
\hline 4 & or/1-3 & 110669 \\
\hline 5 & $\begin{array}{l}\text { government regulation/ or professional autonomy/ or "facility regulation } \\
\text { and control"/ or social control, formal/ or exp jurisprudence/ or exp } \\
\text { credentialing/ or exp "legislation as topic"/ }\end{array}$ & 430853 \\
\hline 6 & $\begin{array}{l}\text { exp health services administration/lj or exp occupational groups/lj or (1 } \\
\text { and lj.fs) }\end{array}$ & 76364 \\
\hline 7 & (legislat* or regulations or regulator ${ }^{*}$ or jurispruden* or statutor ${ }^{*}$ ).ti & 123779 \\
\hline 8 & $\begin{array}{l}\text { (exp patient safety/ or ((patient }{ }^{*} \text { or client* or public) adj3 (safety or } \\
\text { protect }^{*} \text { or interest or interests)).ti,ab,kf.) and (legislat* or regulations or } \\
\left.\text { regulator }^{*} \text { or jurispruden } \text { or statutor }^{*}\right) . \mathrm{ab}, \mathrm{kf}\end{array}$ & 5682 \\
\hline 9 & $\begin{array}{l}\text { (profession* adj2 (registration or licens* } \text { or licenc }^{*} \text { or regulat* }^{*} \text { or } \\
\text { accreditat* }^{*} \text { or credential* or liab* or negligen* or misconduct or } \\
\text { malpractice or college* or board)).ti,ab,kf }\end{array}$ & 4388 \\
\hline 10 & or/5-9 & 580266 \\
\hline 11 & 4 and 10 & 4909 \\
\hline 12 & limit 11 to $y r=" 2015$-Current" & 1792 \\
\hline 13 & limit 12 to english language & 1705 \\
\hline
\end{tabular}




\section{Appendix B: Terminology used for virtual care in the literature}

Remote services: Medical services provided remotely mean those without physical contact, but not necessarily involving long distances.(19)

Telehealth: Telehealth has a broad health promotion and education focus. Based on the concept of telemedicine (expressed below), it has been interpreted to incorporate nursing, pharmacy and allied professions (e.g. rehabilitation).(107) The US Health Resources and Services Administration's definition expands on this interpretation to incorporate "electronic information and tele-communications technologies" to assist with the provision of clinical care from long-distances, "public health and health administration".(29 para 1)Telecommunications technologies can also be used to evaluate, diagnose, and treat patients from afar; $(54,108)$ enable patients to make appointments, view test results, and ask medical questions online; and communicate with health providers via phone, live video, text chat and messages, and mobile applications. $(54,109)$ Other definitions have identified a role for telehealth to coordinate care, manage chronic conditions, and decrease hospital admissions.(110,111) The Center for Connected Health Policy notes that throughout the pandemic, many jurisdictions broadened (at least temporarily) the definition of telehealth, though there is no one consistent definition across the United States. The National Consortium of Telehealth Resource Centers in the US provides a framework for defining telehealth, which they note broadly encompasses four distinct applications: live video, store-and-forward, remote patient monitoring, and mobile health.

Telemedicine: Definitions of telemedicine are numerous and varied. For example, each American state has its own telemedicine definition. $(30,108)$ The umbrella medical regulatory organizations in the United States and Canada also provide definitions of telemedicine. The Federation of State Medical Boards defines telemedicine as "the practice of medicine using electronic communications, information technology, or other means between a licensee in one location and a patient in another location with or without an intervening health care provider" and the Federation of Medical Regulatory Authorities of Canada defines telemedicine as medical service provided remotely (without physical contact but not necessarily involving long distances) via information and communication technology. $(19,112)$ The Center for Connected Health Policy wrote that telemedicine as a term is being phased out in favour of the broader and more inclusive telehealth.(29) The OECD (2020) noted the diversity of definitions of telemedicine hinders comparison across studies.(48)

Virtual care: The definition of virtual care in the literature reviewed was specific to healthcare and contained two elements: remote interactions between patients and individuals within the circle of care, and any form of communication or information technology to make easier or amplify the quality and effectiveness of patient care to the greatest extent possible.(18,113-116) 


\section{For further information, please contact:}

Kathleen Leslie, PhD, JD, RN (principal investigator)

Assistant Professor, Faculty of Health Disciplines, Athabasca University Adjunct Assistant Professor, School of Health Studies, Western University Lead, Governance and Regulation, Canadian Health Workforce Network Email: kleslie@athabascau.ca 